\title{
VII. LA DIPLOMATIE FRANÇAISE ET L'ALLEMAGNE DU LENDEMAIN DE LA PAIX DE WESTPHALIE AU RENVERSEMENT \\ DES ALLIANCES (1648-1756): MISE EN PRATIQUE DES CONNAISSANCES ACQUISES, SOURCE DE CONNAISSANCES NOUVELLES
}

Dans ce chapitre, nous étudierons l'évolution de la politique allemande de la France depuis la signature des traités de Westphalie, en 1648, jusqu'au Renversement des alliances, en 1756. En effet, il paraît indispensable d'analyser les problèmes fondamentaux de cette politique et les axiomes sur lesquels elle se fondait, avant d'examiner la réflexion théorique française sur l'Allemagne et sur son droit public, à travers l'analyse des livres des historiens et des mémoires rédigés par les hommes d'État, les diplomates et les collaborateurs du ministère des Affaires étrangères à Paris, puis à Versailles. Ce sont, notamment, ces derniers mémoires qui retiendront notre attention. Bien que certains auteurs aient depuis longtemps souligné leur valeur pour mieux connaître les opinions qui existaient en France sur l'Allemagne sous l'Ancien Régimel et pour mieux comprendre la politique allemande de la France, ces précieux documents n'ont pas encore fait l'objet d'une étude systématique. Dans cette perspective, notre ambition n'est pas d'analyser minutieusement l'ensemble de la documentation, qui est constituée de plus de cent cinquante volumes, mais de donner une idée générale de sa valeur et d'étu-

\footnotetext{
1 Non seulement des auteurs français (comme Bertrand Auerbach), mais aussi des historiens allemands ont mis en relief la richesse du fonds. En 1904, Preuß insista sur l'importance des mémoires que Le Dran, premier commis du dépôt des archives des Affaires étrangères, avait rédigés sur la part que la France avait prise dans les élections impériales: cf. Georg Friedrich PreuSs, Mazarin und die »Bewerbung « Ludwigs XIV. um die deutsche Kaiserkrone 1657, dans: Historische Vierteljahrschrift 7 (1904), p. 488-518, ici p. 489, n. 1; cf. également Martin GöHRING, Kaiserwahl und Rheinbund von 1658. Ein Höhepunkt des Kampfes zwischen Habsburg und Bourbon um die Beherrschung des Reiches, dans: ID., Alexander ScHARFF (dir.), Geschichtliche Kräfte und Entscheidungen. Festschrift zum fünfundsechzigsten Geburtstage von Otto Becker, Wiesbaden 1954, p. 65-83, ici p. 79, n. 22; pour l'analyse détaillée d'un récit historique retraçant la fondation de la ligue du Rhin, rédigé au XVHIe siècle par un historiographe français par ordre du ministère des Affaires étrangères, récit destiné à l'utilisation interne (»Histoire de l'alliance conclue par le Roy avec plusieurs électeurs et princes de l'Empire appellée communément la ligue du Rhin «; 2 vol.; AE, MD All. 34 et 35), cf. Margarete HINTEREICHER, Der Rheinbund von 1658 und die französische Reichspolitik in einer internen Darstellung des Versailler Außenministeriums des 18. Jahrhunderts, dans: Francia 13 (1985), p. 247-270; enfin, pour l'analyse de la vision de l'Empire de Chavigny, dans un mémoire racontant ses missions de 1712 à 1738, cf. Lucien BÉLY, La place du Saint Empire dans le système européen du XVIII' siècle, dans: Soutou, VALENTIN (dir.), Le statut international de l'Allemagne, p. 663-683, ici p. 670-674.
} 
dier plus précisément certains textes qui ont un intérêt majeur pour connaître l'interprétation que les Français faisaient de la Constitution du Saint-Empire, les sources dont ils se servaient et leur approche méthodique de l'étude du droit public allemand, dont la connaissance était indispensable pour définir les objectifs de la politique allemande du royaume et pour organiser la diplomatie française dans l'Empire.

\section{Le règne de Louis XIV (1648/1661-1715) ${ }^{2}$}

En 1648, la conclusion des traités de Westphalie ne marqua pas la fin de l'antagonisme qui avait caractérisé les rapports entre les Habsbourg de Vienne et de Madrid, d'une part, et les Valois, puis les Bourbons d'autre part. Cet antagonisme était né de la rivalité entre Charles Quint et François Ier, tous deux candidats à l'élection impériale de $1519^{3}$. Depuis cette époque-là, la politique allemande de la France chancelait entre une rhétorique de la défense des »libertés germaniques « des princes allemands, précieux alliés dans le combat des rois de France contre la maison d'Autriche, et une expansion territoriale au détriment du Saint-Empire. De nombreux conflits se déroulaient sur le sol de l'Empire. Pendant un siècle, de 1552 à 1648, le roi de France fut officiellement en guerre avec l'empereur. Le traité de Münster apporta un grand avantage à la France, puisqu'il sépara, du moins de façon provisoire (pour la durée de la guerre franco-espagnole), les deux branches de la maison d'Autriche. En effet, le paragraphe 3 de la paix de Münster interdisait à l'empereur de fournir au roi d'Espagne une quelconque assistance militaire, qu'elle soit directe ou indirecte, bien que la guerre entre la France et l'Espagne concernât entre autres le cercle de Bourgogne, qui était l'un des dix cercles du Saint Empire romain germanique ${ }^{4}$. Cela permettait bien à Mazarin de continuer la guerre contre l'Espagne seule, mais la paix de Münster ne mettait pas la

2 Pour l'histoire de France au temps de Louis XIV, cf. Olivier CHALINE, Le règne de Louis XIV, [Paris] 2005. Dernier bilan des relations franco-allemandes de 1648 à 1789: BRAUN, Von der politischen zur kulturellen Hegemonie.

3 Outre l'étude classique d'AUERBACH, La France et le Saint Empire romain germanique, la première partie de ce chapitre doit beaucoup à l'excellente étude de MALETTKE, Les relations entre la France et le Saint-Empire. Pour l'élection impériale de 1519, cf. également Wilhelm Emst WinTERHAGER, Das Haus Brandenburg und die französische Kaiserkandidatur 1519. Neue Dokumente zur Rolle der Kurfürsten von Brandenburg und Mainz im Kaiserwahlkampf zwischen Habsburg und Frankreich, dans: EXTERNBRINK, ULBERT (dir.), Formen internationaler Beziehungen in der Frühen Neuzeit, p. 299-334.

${ }^{4}$ Selon les commentateurs des premières traductions françaises de la paix de Westphalie, cet article était la clause la plus importante du traité de Münster. Pour le concept de »liberté germanique $\ll$, cf. Albrecht Pius LUTTENBERGER, Libertät. Zur reichspolitischen Tragweite der Kriegspropaganda Frankreichs und seiner deutschen Verbündeten 1552, dans: Heinz DuCHHARDT, Eberhard ScHMITT (dir.), Deutschland und Frankreich in der frühen Neuzeit. Festschrift für Hermann Weber zum 65. Geburtstag, Munich 1987 (Ancien Régime, Aufklärung und Revolution, 12), p. 103-136. 
France à l'abri de la résurgence ultérieure d'une politique concertée entre Madrid et Vienne, après la conclusion de la paix des Pyrénées, en 1659.

Malgré le déclin de la puissance espagnole, qui n'était pas toujours aussi évident pour les contemporains que pour l'historien qui regarde les événements $a$ posteriori, et en dépit de l'affaiblissement de l'autorité impériale, le combat contre la maison d'Autriche continua à être une priorité de la politique étrangère française après les traités de paix de 1648 et de 1659. Le mariage espagnol de Louis XIV ne contribua pas à une détente durable dans ce conflit. En ce qui concerne le Saint-Empire, Léopold Ier réussit à mettre en ouvre une certaine renaissance de l'autorité impériale. Étant donné que les »stratégies de la gloire« de Louis XIV se sont finalement imposées face à celles de Léopold Ier, la postérité n'a pas toujours pris en considération de manière adéquate ce regain d'autorité et de prestige de la part de l'empereur ${ }^{5}$. Cependant, si l'on ne comprend pas que l'Empire n'avait pas échappé à l'empereur avec les traités de Westphalie, et que les forces de l'Allemagne risquaient toujours d'être mises à profit par les Habsbourg dans une guerre contre la France, on ne peut pas expliquer pourquoi la diplomatie française put renouer, après 1648 , avec la vieille rhétorique de son combat contre la "servitude" que la maison d'Autriche imposait aux princes allemands et à l'Europe tout entière. La France put dorénavant se servir de la légitimation de puissance garante de la Constitution allemande qui lui avait été confiée à Münster, dans le paragraphe 114 de la paix du roi avec l'empereur et dans l'article XVII de la paix entre ce dernier et la reine de Suède 6 . En tant qu'élément de la sûreté de la paix, cette garantie des puissances contractantes, qui s'étendait aux affaires intérieures et constitutionnelles allemandes réglées dans les traités de Westphalie, remplaça le système de sécurité collective imaginé par Richelieu. En 1648, il était pourtant

5 Pour les «stratégies de la gloire« de Louis XIV, cf. l'ouvrage classique de BURKE, Louis XIV. Pour Léopold Ier, cf. Goloubeva, Glorification; Jutta SchumanN, Die andere Sonne: Kaiserbild und Medienstrategien im Zeitalter Leopolds I., Berlin 2003 (Colloquia Augustana, 17); et surtout la récente biographie de BÉRENGER, Leopold Ier.

${ }^{6}$ La façon dont ce statut fut utilisé par la diplomatie française en Allemagne n'a pas encore fait l'objet d'une étude systématique. Cependant, on peut dire que, peu utilisée au lendemain de la guerre de Trente Ans, cette condition de puissance garante fut plus souvent mise en avant à partir du moment où la France perdit un précieux instrument d'intervention dans l'Empire avec la dissolution de la première ligue du Rhin (1658-1668), placée sous son égide, et que le recours à ce droit fut fréquent au XVIlle siècle. Au cours de la guerre de Sept Ans (1756-1763), la France s'exposa de plus en plus à la critique: on lui reprochait d'utiliser cette légitimation comme un prétexte pour mener dans l'Empire, et surtout dans l'électorat de Hanovre, une guerre qui était en réalité dirigée contre l'Angleterre. Dans un mémoire datant de la période 1715-1740, un collaborateur du ministère français des Affaires étrangères avait déjà constaté: »comme les guerres ont depuis été presque continuelles entre cette couronne et l'Empire, le droit de garantie des traitez de Westphalie, quoique renouvellé et confirmé par les traittez de paix de Nimègue, de Riswick et de Bade, n'a presque plus été regardé que comme un vain titre dont la France ne se prévaloit qu'à dessein de tâcher d'engager quelques-uns des princes de l'Empire dans ses intérests, de les soulever contre l'Empereur, et de jetter et entretenir en Allemagne des semences perpétuelles de troubles et de dissensions «, cf. le mémoire intitulé »De la garantie de la France sur les traités de Westphalie«, copie: AE, MD All. 78 fol. 528-534, citation fol. 530-530'. 
difficile de savoir quel rôle cette garantie pourrait jouer à l'avenir, puisque les traités de Westphalie ne précisaient pas les conditions d'application de ce droit d'intervention politique comme protecteur de la Constitution allemande 7 . Pour leur part, les rois de France ne restreignaient pas son exercice aux seuls problèmes de la Constitution allemande réglés dans la paix de Westphalie, mais en déduisaient un droit légitime à veiller au respect de sa Constitution en général. Un mémoire rédigé au ministère des Affaires étrangères entre 1715 et 1740 formula cette prétention française de la manière suivante:

le Roy Louis XIV s'en est prévalu en plusieurs occasions pour prendre part aux affaires intérieures de l'Empire à titre de garant des traitez de Westphalie, et il a même quelques fois prétendu que cette garantie était moins une obligation qu'un droit qui l'autorisoit à avoir une inspection principale sur les affaires publiques d'Allemagne ${ }^{8}$.

Comme nous le verrons dans notre chapitre sur la France et les frontières du Saint Empire romain germanique, Mazarin et Louis XIV ne réussirent pas, dans les années 1650 et 1660 , à faire admettre le roi de France comme membre de l'Empire en sa qualité de landgrave d'Alsace. L'année 1658 constitua un double tournant: d'abord, la France échoua dans son dessein d'empêcher l'élection de l'archiduc Léopold comme empereur, mais ensuite elle remporta un succès avec la conclusion de la ligue du Rhin.

L'interrègne avait pourtant fourni une occasion propice à la réalisation de ce vieux rêve de la diplomatie française. Dans la décennie suivant la paix de Westphalie, les Habsbourg réussirent donc à deux reprises à imposer leurs candidats: d'abord Ferdinand IV, pourtant mort avant son père', l'empereur Ferdinand III, puis Léopold Ier, élu en 1658. Alors que la royauté française sortait à peine de la Fronde, la puissance des Habsbourg se montrait moins compromise qu'il avait pu paraître en 1648. La longévité de Léopold Ier, décédé en 1705, procura à la maison d'Autriche une longue période pendant laquelle son rôle traditionnel de dynastie impériale ne fut pas remis en cause. L'élection d'un Habsbourg fut donc le véritable échec de la politique du cardinal Mazarin en 1658. En revanche, l'idée de la candidature de Louis XIV, à peine ébauchée dans l'esprit du cardinal, et jamais sérieusement discutée à l'assemblée élective de Francfort, ne représentait pas un pivot de la diplomatie française. En effet, la France avait d'abord soutenu la candidature de Ferdinand-Marie de Bavière, qui refusa pourtant de se présenter, puis celle de Philippe-Guillaume de Neubourg. Bien que la candidature du Roi Très Chrétien ne fût pas un véritable enjeu de la politique européenne en 1657, Voltaire lui accorda une importance majeure dans son »Siècle de Louis XIV ${ }$. Au XIX et

${ }^{7}$ Cf. Karl Otmar [Freiherr] vON ARETIN, Reichssystem, Friedensgarantie und europäisches Gleichgewicht, dans: ID., Das Reich. Friedensgarantie und europäisches Gleichgewicht 1648-1806, Stuttgart 1986, p. 55-75.

8 »De la garantie de la France sur les traités de Westphalie«, AE, MD All. 78 fol. 528-534 (voir ci-dessus), ici fol. 529.

${ }^{9}$ Ferdinand IV (1633-1654), en 1646 roi de Bohême, en 1647 roi de Hongrie, élu roi des Romains en 1653. 
au XXe siècle, cette affaire fit couler beaucoup d'encre des deux côtés du Rhin. Dans la perspective des relations franco-allemandes, ce sujet revêtit donc une importance plus grande en tant que problème historiographique qu'en tant que problème historique. Derrière cette querelle, il y a la question plus essentielle qui consiste à savoir si la candidature d'un roi de France était véritablement une option sérieusement envisagée par la politique française ${ }^{10}$. Louis XIV aspirait-il à l'Empire? Dans ce chapitre, notre propos n'est pas de trancher cette question ${ }^{11}$, mais de rappeler certaines étapes historiographiques qui témoignent de la passion avec laquelle la question fut discutée des deux côtés du Rhin.

En 1897, Henri Vast souligna le fait que plusieurs étrangers avaient déjà été élus empereurs au Moyen Âge (il mentionne les élections d'Alphonse de Castille et de Richard de Cornouailles) ${ }^{12}$. Selon lui, la candidature d'un roi de France n'aurait donc rien eu d'exceptionnel. Vast signala également que, après 1658 , Louis XIV conclut plusieurs traités ou articles secrets avec des princes électeurs de l'Empire pour s'assurer leurs voix (pour lui ou pour le candidat soutenu par la France) lors de l'élection suivante. Vast pensait aux traités conclus avec la Saxe, la Bavière et le Brandebourg, à partir de 1664 et jusqu'en 167913. Mais il concédait que le roi n'avait pas eu la possibilité de profiter de ces préparatifs diplomatiques ${ }^{14}$. À la différence de Vast, Legrelle prétend que ces traités étaient »d'une

10 Ce sujet n'a plus été traité de manière systématique depuis l'article de ZELLER, Les rois de France candidats à l'Empire. Mais cet article n'apparaît pas comme une réponse définitive à la question. Pour la période antérieure à 1648 , on peut se reporter aux pages que BABEL, Deutschland und Frankreich, consacre aux rapports entre regnum et imperium, p. 155-165, ainsi qu'à la contribution de Winfried DoTZAUER, Heinrich IV. von Frankreich und die Frage der römischen Königswahl in Deutschland, dans: Zeitschrift für die Geschichte des Oberrheins 114 (1966), p. 71-146.

11 Pour l'état actuel des connaissances sur l'élection de 1658, qui fut »l'une des plus dramatiques de l'époque moderne«, cf. MALETTKE, Les relations entre la France et le Saint-Empire, p. 237-248; BÉRENGER, Léopold Ier, p. 199-202 et p. 211-221 (citation p. 211). Toujours utile: le livre second, intitulé $» L$ 'élection de l'empereur Léopold I ${ }^{\text {er }}$ et la constitution de la Ligue du Rhin«, dans: J[ules] VALFREY, Hugues de Lionne. [Avant-titre:] La diplomatie française au XVIIe siècle, [vol. II:] Ses ambassades en Espagne et en Allemagne, la paix des Pyrénées. D'après sa correspondance conservée aux Archives du Ministère des Affaires étrangères, Paris 1881 , p. 65-176.

12 Pour ce problème, cf. également Heinz DuchHard, Et Germani eligunt et Germanus eligendus. Die Zulassung ausländischer Fürsten zum Kaiseramt im Jus Publicum des 17./ 18. Jahrhunderts, dans: Zeitschrift der Savigny-Stiftung für Rechtsgeschichte, Germanistische Abteilung 97 (1980), p. 232-253.

${ }^{13} \mathrm{Cf}$. H[enri] VAST, Des tentatives de Louis XIV pour arriver à l'Empire, dans: Revue historique 65 (1897), p. 1-45; il publie le traité conclu avec Brandebourg le 25 octobre 1679 , ibid., p. 35-41 (le traité avec la Saxe de 1679 est presque identique). Pourtant, plusieurs historiens allemands ont souligné le fait que le traité conclu avec la Saxe en 1664 n'avait rien à voir avec les projets de candidature, cf. W[alter] PLATZHOFF, Ludwig XIV., das Kaisertum und die europäische Krisis von 1683, dans: Historische Zeitschrift 121 (1920), p. 377-412, ici p. 380 , n. 3.

14 En 1686, Léopold Ier assura sa succession en faisant élire à Augsbourg son fils aîné, l'archiduc Joseph, âgé de huit ans. 
impossibilité évidente de réussir«, et en conclut que Louis XIV ne prétendait pas sérieusement à l'Empire ${ }^{15}$.

En 1888, Pribram avait déjà publié un article dans lequel il défendait le caractère sérieux de la candidature de Louis XIV en 1657. Il pensait que c'était à tort qu'au XIX'e siècle une partie de l'historiographie française avait remis en question sa candidature, déjà évoquée par Voltaire, à travers une analyse peu critique des mémoires du duc de Gramont. Pribram soulignait que, dans son discours tenu devant l'Académie des sciences morales et politiques, en 1886, Adolphe Chéruel avait réfuté les arguments allégués contre l'idée de la candidature du Roi Très Chrétien; cependant, il concédait que Lemontey avait exagéré la part personnelle du roi dans cette affaire, dans son »Essai sur l'établissement monarchique de Louis XIV«, publié à Paris, en 1818, l'idée de sa candidature ayant surtout été conçue par Mazarin ${ }^{16}$. Pribram admettait aussi que, parmi les princes allemands, la France avait préféré soutenir les candidatures éventuelles de Ferdinand-Marie de Bavière, puis de Philippe-Guillaume de Neubourg ${ }^{17}$. Or, les travaux de Pribram et de Vast ne furent pas approuvés de façon unanime.

En 1904, Preuß proposa une étude plus nuancée et plus critique de la question de la candidature de Louis XIV18 et déclara son accord avec Pribram à propos du soutien accordé par la France aux princes de Bavière et de Neubourg. Toutefois, il pensait que Mazarin n'avait caressé que pour un moment l'idée d'une candidature de Louis XIV, soulignant qu'aucun diplomate français n'avait jamais reçu l'ordre de proposer ou de soutenir immédiatement et formellement cette candidature. Preuß montre que l'idée de la candidature de Louis XIV ne venait ni de Mazarin ni de Gravel, mais qu'elle leur avait été suggérée par des Allemands, en particulier par l'entourage de l'archevêque de Mayence (sans que les Allemands approuvassent réellement une telle candidature), et que le cardinal ne l'avait accueillie qu'avec une très grande prudence, ne voulant poursuivre sérieusement ce projet que lorsqu'on serait sûr de le faire réussir. Le seul ordre concret que le cardinal donna au sujet de cette candidature se trouve dans une lettre envoyée à Gravel, le 23 juin 1657. Mazarin ordonna à ce dernier de n'en parler au chancelier de Mayence, Boineburg, que si une occasion très favorable se présentait, et de manière extrêmement prudente, puisqu'il craignait l'opposition de la Suède et des princes protestants de l'Empire ${ }^{19}$. Au printemps, Gravel avait rapporté au cardinal que

15 Cf. A. LEgRELLE, Louis XIV a-t-il voulu devenir Empereur?, dans: Bulletin critique, deuxième série, t. III (1897), p. 694-703, ici p. 696 (citation) et p. 697.

16 Cf. Alfred Francis PRIBRAM, Zur Wahl Leopold I. 1654-1658, dans: Archiv für österreichische Geschichte 73 (1888), p. 79-222, en particulier son aperçu de l'historiographie française sur ce sujet p. 182, n. 1 .

17 Cf. ibid., p. 192 , n. 3.

18 PrEUSS, Mazarin und die »Bewerbung « Ludwigs XIV. Comme Pribram, Preuß avait également la possibilité d'utiliser les correspondances diplomatiques du Quai d'Orsay.

19 Cf. ibid., p. 494-496, p. 500-501 et p. 503; cf. également la lettre envoyée par Mazarin à Gravel, La Fère, 23 juin 1657, extrait dans: MAZARIN, Lettres, t. VII, p. 521-527, ici p. 525526: Mazarin autorise Gravel à payer immédiatement à l'électeur de Mayence jusqu'à trente mille thalers et à lui promettre d'autres bénéfices »pour sa personne, pour ses parents ou pour 
certains députés allemands et l'archevêque Jean-Philippe de Mayence avaient évoqué une éventuelle candidature de Louis XIV, mais l'envoyé français en rendait compte d'une manière qui montrait qu'il n'avait reçu aucun ordre d'en faire la proposition de la part du gouvernement français ${ }^{20}$. Le 29 juillet 1657, Mazarin envisagea la proposition de la candidature de Louis XIV pour le cas où l'élection de Bavière ou de Neubourg s'avérerait impossible et à condition d'obtenir le soutien de Brandebourg et du palatin, afin d'empêcher la candidature d'un Habsbourg. Le 5 août, le cardinal disait toujours à Servien »qu'il ne pourroit rien arriver de plus advantageux au Roy que l'elevation « du duc de Neubourg ${ }^{21}$. Preuß souligne que le véritable objectif de la politique de Mazarin était d'éviter l'élection d'un Habsbourg 22. Il approuve entièrement la phrase de conclusion d'Henri Martin, qui est en accord avec les mémoires de Brienne ${ }^{23}$, mais qui est souvent citée de façon incorrecte (en particulier par Pribram, comme le lui reproche Preuß). Toutefois, Preuß insiste sur la deuxième partie de cette phrase, qui représente selon lui la véritable opinion de Martinn24: Mazarin ne pensa à la candidature de Louis XIV »que pour le cas où l'on ne pourrait trouver de candidat allemand«. Preuß réfute toutes les assertions moins prudentes, mais contredit également les auteurs qui nient toute idée de candidature de Louis XIV. Cependant, cet auteur pensait qu'il valait mieux éviter de parler de »candidature«, car ce terme suggérait l'idée d'un acte formel et sérieux, à moins que l'on n'entende par là qu'un "projet d'avenir éphémère de la part de Mazarin «25. Preuß reprochait à Vast, dans son article de 1897, de ne pas avoir pris en considération les contributions récentes en langue allemande à ce sujet, fussent-elles en accord (comme l'article de Pribram) ou en désaccord avec sa propre position. Preuß examina plus minutieusement que Pribram l'historiographie française et allemande au sujet de cette prétendue candidature; selon Preuß, le désaccord existant entre les historiens ne suivait pas le

ses domestiques [...]. Vous sçaurez aussy dans la derniere confiance, et sans en parler à personne, que, quoyqu'on parle du Roy avec cette retenue, si neantmoins on voyoit jour à pouvoir faire eslire Sa $\mathbf{M}^{\text {té }}$, on eslargiroit, pour cela, la main bien davantage. Il faut faire là-dessus la guerre à l'œil, et, si vous voyiez que les choses s'y puissent disposer, vous pourriez en laisser eschapper quelque mot delicatement, et comme de vous-mesme, audict sieur de Bennebourg, pour penetrer quel seroit en cela le sentiment de $M$. de Mayence. Je croy pourtant que le roy de Suede et la plus grande partie des protestants seroient fort contraires à cette eslection du Roy«.

20 Cf. PReuss, Mazarin und die »Bewerbung« Ludwigs XIV., p. 496-500 et p. 503.

21 Cf. ibid., p. $491-493$ et p. 504 (citation).

22 Cf. ibid., p. 510-511.

${ }^{23}$ Cf. Henri Martin, Histoire de France depuis les temps les plus reculés jusqu'en 1789, t. XII, Paris ${ }^{4} 1858$, p. 505; voici la phrase complète: »Quoi qu'en ait dit un historien moderne [Lemontey], Mazarin ne pensa pas sérieusement à faire élire Louis XIV empereur, ou, du moins, il n'y pensa que pour le cas où l'on ne pourrait trouver de candidat allemand, et, sans s'attacher à cette idée dangereuse, il eût vivement souhaité d'opposer comme candidat au roi de Hongrie l'électeur de Bavière, idée déjà ancienne dans la diplomatie française «. Toutefois, selon Martin, le témoignage de Brienne mérite "fort peu de considération« (ibid., n. 1). ${ }^{24}$ Cf. Preuss, Mazarin und die »Bewerbung « Ludwigs XIV., p. 493-494; même la citation de Preuß n'est pas tout à fait correcte.

25 Ibid., p. 517: »kurzen Zukunftsplan Mazarins«. 
clivage national entre les auteurs allemands et français ${ }^{26}$, puisque l'idée de la candidature formelle de Louis XIV trouva des adeptes en France (notamment Flassan) et en Allemagne.

Les conclusions de Preuß n'ont pas reçu l'aval de Göhring, qui, en 1954, estimait que Mazarin aurait considéré l'élection de Louis XIV comme le »couronnement « de sa politique, tout en admettant que le cardinal n'avait pas osé proposer officiellement sa candidature ${ }^{27}$. Pour Göhring, la recherche du titre impérial par les rois de France depuis le Moyen Âge était un axiome qu'il formulait au début de son article et qui déterminait ses conclusions. Toutes les dynasties françaises des Capétiens aux Bourbons auraient cherché à récupérer la couronne impériale. Toujours selon Göhring, Louis XIV fit de sérieuses tentatives pour se faire élire empereur, après 1658 . Toutefois, cet auteur n'apporta pas de sources nouvelles pour justifier ses hypothèses.

À la différence de Göhring, en 1912, Bertrand Auerbach estima que l'influence de la tradition de la pensée juridique française méritait peu de considération dans le contexte de l'élection de 1658. Selon lui, la France »ne céda pas au rêve triomphant du Roi de France sous la figure et l'appareil du César Romain Germanique: vision chère sans doute à ses hommes d'Etat, à ses juristes, qui, au nom du droit historique, revendiquaient pour leur Roi l'héritage de l'Empire de Charlemagne! Mazarin, plus réaliste borna sa diplomatie à évincer le candidat autrichien $\ll^{28}$.

En 2001, Klaus Malettke estima que

juger ainsi [comme Auerbach], c'est méconnaître l'habileté et la richesse en variantes de la diplomatie mazarine. Dans les années 1657 et 1658 , la candidature éventuelle du Roi de France, celle de l'électeur de Bavière ou du comte-palatin de Neubourg, et le projet de former une union des princes allemands furent pour Mazarin des moyens importants et sérieux pour empêcher l'élection d'un Habsbourg ou, au cas où ce but principal ne pourrait pas être réalisé, pour réduire autant que possible les moyens d'agir d'un Empereur appartenant à la Maison d'Autriche. Pour Mazarin, le recours à une ou deux de ces alternatives dépendait des conjonctures politiques et des éventuelles circonstances favorables.

\section{Et d'ajouter:}

Tous les indices sérieux dont nous disposons, nous signalent que Mazarin envisagea, de mai à juillet 1657 , de faire poser la candidature de Louis XIV à la couronne impériale, si une chance réelle se présentait à lui. Certes, les instructions envoyées aux diplomates français résidant en Allemagne furent extrêmement prudentes, mais ceci est tout à fait compréhensible, car Mazarin connaissait fort bien les susceptibilités des princes-électeurs et des États d'Empire. Et il ne voulait pas, d'autre part, risquer de compromettre l'honneur et la réputation du

26 Cf. ibid., p. 515 , n. 1.

${ }^{27}$ Cf. GöHRING, Kaiserwahl und Rheinbund von 1658, en particulier p. 76-78. Cf. également la lettre envoyée par Mazarin à Gravel, Stenay, 15 juillet 1657, extrait dans: MAZARIN, Lettres, t. VIII, p. 35-38, ici p. 37: »il seroit bon de sçavoir precisement quelles sont les intentions dudict sieur Electeur [de Mayence] à l'esgard de l'eslevation du Roy, et quand vous le verriez disposé à cela, [...] vous luy [sc. à l'électeur de Mayence] direz, de ma part, que je le conjure de ne vouloir, en aucune façon, permettre qu'il soit parlé de la dignité imperiale pour le Roy, sans estre asseuré qu'infailliblement la chose reussirau.

28 AUERBACH, La France et le Saint Empire romain germanique, p. 55. 
Roi et la sienne propre, en présentant publiquement une candidature sans être assuré que le projet réussirait ${ }^{29}$.

Pour autant, peut-on parler d'une véritable »campagne de presse« pour propager les prétentions du Roi Très Chrétien et conclure que "Mazarin se trompa sur les possibilités de réaliser ses intentions « $^{30}$ ? Valfrey pense également que le cardinal ne comprit pas à temps la situation, avant de se rallier in extremis à la nomination de Léopold I ${ }^{\mathrm{e}}$; pourtant, il estime que les lettres fictives publiées à l'instigation de Mazarin pour porter l'opinion vers le roi de France ne constituaient qu'une sorte de combat d'arrière-garde. En effet, les ambassadeurs de Louis XIV, qui en reçurent une grande quantité, ne pouvaient les distribuer sans en trahir l'origine ${ }^{31}$. Suzanne Pillorget parle (comme Henri Vast) d'une »véritable >campagne de presse « $«$ mais elle concède que le »Manifeste des Français aux Princes Electeurs assemblés pour l'élection d'un Empereur à Francfort «, qui osait hardiment poser la candidature de Louis XIV, ne fut pas publié ${ }^{32}$.

Toutefois, il est certain que »Mazarin songea au mois de juin 1657 à présenter sérieusement la candidature de Louis XIV à l'Empire puis il se ravisa, parce qu'il estima que cette candidature serait une grave erreur; le Roi Très Chrétien se contenterait d'exercer une tutelle et non le pouvoir $\ll^{33}$.

Dans un article publié en $1920^{34}$, l'historien allemand Platzhoff souligna qu'une candidature de Louis XIV avait été évoquée à trois reprises: en 1657/1658,

29 Malettke, La France et le Saint-Empire, p. 242.

$30 \mathrm{Cf}$. ibid., p. 243. Cette notion est refusée par plusieurs auteurs, en particulier par S[tefanus] F[rançois] N[audé] GIE, Die Kandidatur Ludwigs XIV. bei der Kaiserwahl vom Jahre 1658 mit besonderer Berücksichtigung der Vorgeschichte, Berlin, Leipzig 1916 (Abhandlungen zur Mittleren und Neueren Geschichte, 61), p. 99.

31 Cf. Valfrey, Hugues de Lionne, p. 115-118.

32 Cf. Suzanne PILLORGET-RouAneT, Louis XIV candidat au trône impérial (1658). Un document inédit, dans: Revue d'histoire diplomatique 81 (1967), p. 5-17, citation p. 6. L'auteur souligne aussi que, malgré cette propagande, »les instructions envoyées aux diplomates français résidant en Allemagne furent extrêmement prudentes« (ibid.). Le »Manifeste« présentait le Roi Très Chrétien comme un prince »originairement allemand« (puisque d'origine franque) et évoquait la »conformité des lois, des coutumes et des manières d'agir « françaises et allemandes qui était »une marque infaillible qu'elles [la France et l'Allemagne] n'ont été autrefois qu'une [seule nation] « (ibid., p. 13-14). Mais les publicistes français ne pouvaient pas tromper l'opinion publique allemande: »le roi de France, dont les troupes surclassaient décidément celles du roi d'Espagne et qui se trouvait désormais allié à la République anglaise, devenait alors un prince beaucoup plus puissant que le jeune Léopold, roi de Bohême et de Hongrie. Donc, beaucoup plus dangereux pour leur Landeshoheit, pour la >liberté des Allemagnes` [évoquée dans le `Manifeste‘]. Ce rapport de forces allait déterminer le choix des Electeurs« (ibid., p. 17).

${ }^{33}$ Cf. BÉRENGer, Léopold Ier, p. 213-214 et p. 216-217 (citation p. 214). Cf. aussi VALFREY, Hugues de Lionne, p. 74: »Louis XIV allait-il renouveler la tentative funeste de François Ier et prétendre pour lui-même à la succession de Ferdinand III? Mazarin n'eut garde de lui laisser commettre une telle faute. C'était la tutelle et non l'exercice de l'Empire qu'il voulait pour le Roi, en s'inspirant des combinaisons que le génie de Richelieu avait enfantées«.

34 PlatZhoff, Ludwig XIV., das Kaisertum und die europäische Krisis. Parmi les travaux anciens, voir aussi GrE, Die Kandidatur Ludwigs XIV., qui parle d'une tentative sérieuse de Mazarin pour faire élire Louis XIV. Cet auteur est pratiquement le seul à étudier d'une ma- 
en 1669/1670 et de 1679 à 1682 . Il admettait également que le renouvellement de l'empire de Charlemagne n'avait cessé de fasciner la France depuis Philippe le Bel. Mais cet historien constatait un décalage entre la portée réelle des projets louis-quatorziens et l'opinion de nombreux contemporains qui ne doutaient pas de l'aspiration du Roi-Soleil à l'Empire ${ }^{35}$. Ce dernier aspect est particulièrement important pour notre étude: pour ses contemporains, une éventuelle candidature de Louis XIV n'était pas exclue ${ }^{36}$. Cette particularité ne doit être négligée ni dans l'étude de l'opinion publique allemande face au Roi-Soleil, ni dans l'analyse de la façon dont les auteurs français interprétaient le Saint-Empire. Sous l'Ancien Régime, la réminiscence de l'Empire carolingien ne fut jamais véritablement éclipsée de l'imaginaire politique de la royauté française ${ }^{37}$. Mais l'aspiration à l'Empire ne constitua jamais pour autant un sujet d'actualité politique pour Louis XIV, et moins encore pour ses successeurs. À cet égard, le seul souci du Roi-Soleil (et de Mazarin) était de conserver à la monarchie des options pour l'avenir.

L'échec que Mazarin essuya, en 1658, en s'opposant au candidat de la maison d'Autriche, fut pourtant atténué par les articles 13,14 et 16 de la capitulation de Léopold (adoptés le 15 mai 1658), qui interdirent à ce dernier d'accorder aucune

nière détaillée la période précédant la mort de Ferdinand III. Gie conclut qu'entre 1654 et 1657 Mazarin avait déjà pris conscience des difficultés que poseraient une candidature bavaroise ou celle de Neubourg, de sorte qu'il se vit contraint de penser à la candidature de Louis XIV en 1657.

35 Cf. Platzhoff, Ludwig XIV., das Kaisertum und die europäische Krisis, p. 377.

${ }^{36}$ Cf. Alexander SCHMidT, Ein französischer Kaiser? Die Diskussion um die Nationalität des Reichsoberhauptes im 17. Jahrhundert, dans: Historisches Jahrbuch 123 (2003), p. 149 177, en particulier la conclusion p. 174.

37 Cf. Victor-L[ucien] TAPIE, Europe et chrétienté. Idée chrétienne et gloire dynastique dans la politique européenne au moment du siège de Vienne (1683), dans: Gregorianum 42 (1961), p. 268-289, ici p. 271-272: "Que Louis XIV ait pensé à la couronne d'Empereur, comme l'avait fait avant lui François Ier, la chose est bien connue. Lors de l'élection impériale de 1658 , il n'y avait point eu de candidature déclarée du roi de France, parce que Mazarin, après quelques informations, avait préféré ne pas courir le risque d'un échec, mais on y avait pensé. Vingt ans plus tard, après Nimègue, Louis XIV continuait à regretter que la dignité impériale eût été détournée ‘des princes de son sang`. Il s'applique à enseigner à son fils que la dignité actuelle des Empereurs n'est point comparable à celle des empereurs romains, ni de Charlemagne; ils sont tout au plus les chefs et capitaines généraux d'une république d'Allemagne, sans supériorité sur les nations voisines. N'empêche que ce titre d'Empereur devrait revenir au prince le plus fort et qu'après avoir peiné à en démontrer le caractère vain, il arrivait à Louis XIV de le solliciter pour lui-même. En 1679, il demandait à l'électeur de Bavière, en cas de mort de l'Empereur, de s'employer fortement [...] à faire élire Sa Majesté, et l'argument qu'il invoquait pour justifier son ambition était précisément le péril turc. [...] Tel était, à l'heure de sa toute puissance, dans cette curieuse sollicitation de Louis XIV, l'aveu indirect qu'il manquait quelque chose à sa gloire, peut-être à la réalité de sa puissance, tant qu'il ne posséderait pas le titre suprême et n'exercerait point, par lui, de suzeraineté sur l'Empire. [Après Münster, Aix-la-Chapelle et Nimègue] il était hors de doute que la prépondérance française [...] ressemblait à un Empire sans le titre, mais que l'existence, en une autre maison royale, de la couronne et de la dignité impériales la condamnait à une sorte de précarité et d'inachèvement «. Mais l'élection impériale n'était pas à l'ordre du jour. 
aide à l'Espagne durant sa guerre contre la France ${ }^{38}$. En effet, Jean Bérenger estime que le »but de Mazarin n'était pas de faire élire Louis XIV, mais de peser sur les électeurs pour écarter les Habsbourg ou tout au moins lier le futur empereur par des capitulations draconiennes, qui priveraient Philippe IV de toute aide allemande $\ll$ 39.

En outre, la diplomatie française remporta un succès majeur, le 14 août 1658 , avec la conclusion de la ligue du Rhin, qui lui fournit un instrument de taille pour intervenir dans les affaires intérieures de l'Allemagne. Cette ligue fut »la consécration de l'action diplomatique tenace menée en Allemagne par Mazarin depuis la fin de la guerre de Trente Ans«, son »chef-d'œuvre diplomatique« et »une entrave à la liberté d'action de Léopold durant une décennie « ${ }^{40}$. La ligue du Rhin comptait parmi ses premiers signataires les archevêques de Mayence et de Cologne, le palatin de Neubourg, les trois ducs de la maison de Brunswick, la HesseCassel et la Suède (pour ses possessions allemandes à Brême et Verden); le lendemain, 15 août 1658, la France s'y joignit comme puissance garante de la paix de Westphalie. L'instigateur de cette première ligue du Rhin (la deuxième ligue du Rhin fut fondée par Napoléon I I'r, en 1806), l'archevêque Jean-Philippe de Mayence, pensait que l'élection d'un archiduc d'Autriche à la tête de l'Empire et la conclusion d'une alliance comprenant la France pouvaient éviter la domination d'une seule grande puissance, au détriment de la liberté des états de l'Empire. Dans cette perspective, la survie de cette confédération comme instrument de la sûreté de la paix dépendait de la politique pacifique de la France. Au cours des dernières années du ministère de Mazarin, qui furent marquées par la conclusion de la paix des Pyrénées, ce rôle pacificateur de la France semblait acquis. Par conséquent, d'autres princes territoriaux rejoignirent la ligue: en 1660, le prince-évêque de Münster; en 1662, le prince électeur de Trèves; en 1665, le prince électeur de Brandebourg. En revanche, la politique expansionniste et plus agressive que Louis XIV mena à l'encontre de l'Espagne, aux Pays-Bas et puis en Allemagne ne pouvait que détruire la ligue du Rhin, qui ne fut plus renouvelée en 1668 . La guerre de Dévolution entamée par Louis XIV dans les Pays-Bas espagnols, en 1667, et dont la paix, signée à Aix-la-Chapelle en 1668, apporta à la France une partie de la Flandre avec Lille, montra à l' archevêque Jean-Philippe de Mayence que le roi de France était certainement un allié et un protecteur plus dangereux pour sa propre principauté et pour les princes d'Allemagne que l'empereur ${ }^{4 l}$.

Le procédé de Louis XIV à l'encontre des princes allemands était l'expression d'une nouvelle conception de la politique allemande de la France. Le legs de Richelieu, déjà sensiblement entamé sous Mazarin, fut définitivement abandonné.

\section{Cf. BÉRENGER, Léopold Ier, p. 218-219.}

39 Ibid., p. 212. En contravention avec la paix de Münster ( $\$ 3$ ), la cour de Vienne avait permis au roi d'Espagne de faire des levées en Allemagne, et Ferdinand III avait même transféré des troupes aux Pays-Bas espagnols; cf. ibid., p. 217-218.

40 Ibid., p. 220.

41 Cf. Claude Badalo-Dulong, Trente ans de diplomatie française en Allemagne. Louis XIV et l'électeur de Mayence (1648-1678), Paris 1956, p. 139. 
Cet héritage consistait en une conception collective de la sûreté. À la différence des cardinaux, Louis XIV opta pour un emploi plus résolu de la force physique et chercha plus à imposer sa volonté par sa puissance qu'à réconcilier la France avec les princes d'Allemagne ${ }^{42}$. Les projets de sûreté collective furent remplacés par des alliances bilatérales passées avec un certain nombre de princes dans l'Empire. Ce changement majeur n'affecta pourtant pas la rhétorique de la diplomatie française, le roi continuant à se présenter en protecteur des libertés germaniques ${ }^{43}$. Avec un succès mitigé, la diplomatie française dispensa aux princes allemands des subsides qui, à la différence de ce qui se pratiquait du temps de la guerre de Trente Ans, ne furent plus exclusivement employés pour les armées et pour la guerre, mais pour l'architecture, la vie de cour et le mécénat des artistes. Consciente de l'échec relatif de cette politique ${ }^{44}$, la régence de Philippe d'Orléans (1715-1723) rompit provisoirement avec la politique des subsides ${ }^{45}$, mais Louis XV renoua bientôt avec cette tradition ${ }^{46}$, qui ne fut abandonnée définitivement qu'après la guerre de Sept $\mathrm{Ans}^{47}$.

L'année 1672 marqua le début d'une épreuve plus rude pour les princes allemands que ne l'avait été la guerre de Dévolution. En effet, cette nouvelle guerre que Louis XIV commença cette fois contre les Provinces-Unies des Pays-Bas intéressa directement l'ouest de l'Empire, à partir de 1673. La France et son allié suédois réclamèrent la garantie du respect de la paix de Westphalie pour empêcher

$42 \mathrm{Au}$ sujet de la nature fondamentale de ce changement de méthode et de priorité, que l'archevêque de Mayence comprit très vite, cf. Max BRAUBACH, Wilhelm von Fürstenberg (1629-1704) und die französische Politik im Zeitalter Ludwigs XIV., Bonn 1972 (Bonner Historische Forschungen, 36), en particulier p. 95-96; Karl Otmar Freiherr vON ARETIN, Die Kreisassoziationen in der Politik der Mainzer Kurfürsten Johann Philipp und Lothar Franz von Schönborn 1648-1711, dans: ID. (dir.), Der Kurfürst von Mainz und die Kreisassoziationen 1648-1746. Zur verfassungsmäßigen Stellung der Reichskreise nach dem Westfälischen Frieden, Wiesbaden 1975 (Veröffentlichungen des Instituts für Europäische Geschichte Mainz, Abteilung Universalgeschichte, cahier suppl. 2), p. 31-67, en particulier p. 43-44. 43 C'est pourquoi, au début de ce livre, il était important d'examiner de manière minutieuse la politique allemande du cardinal de Richelieu, puisqu'elle continua à fournir le fondement idéologique de la politique française en Allemagne et l'autoreprésentation de la diplomatie du Roi Très Chrétien, même après que ses priorités eurent changé.

44 Cf., par exemple, Janine FAYARD, Les tentatives de constitution d'un $»$ tiers party « en Allemagne du Nord (1690-1694), dans: Revue d'histoire diplomatique 79 (1965), p. 338-372, en particulier p. 368-372: de 1691 à 1693 , le roi versa 6,2 millions de livres de subsides aux princes de Münster, de Saxe-Gotha, de Wolfenbüttel et de Hanovre ainsi qu'au roi de Danemark sans parvenir à la constitution d'un tiers parti en Allemagne du Nord.

45 Cf. UlberT, Frankreichs Deutschlandpolitik.

46 Cf. Peter Claus HaRTMANN, Geld als Instrument europäischer Machtpolitik im Zeitalter des Merkantilismus. Studien zu den finanziellen und politischen Beziehungen der Wittelsbacher Territorien Kurbayern, Kurpfalz und Kurköln mit Frankreich und dem Kaiser von 1715 bis 1740, Munich 1978 (Studien zur bayerischen Verfassungs- und Sozialgeschichte, 8).

${ }^{47}$ Entre la fin de la guerre et la Révolution française, seul le duc de Palatinat/Deux-Ponts, héritier présomptif des électeurs palatin et bavarois, continua à toucher les subsides français. Cf. Eckhard BudDruss, Die französische Deutschlandpolitik 1756-1789, Mayence 1995 (Veröffentlichungen des Instituts für Europäische Geschichte Mainz, Abteilung Universalgeschichte, 157), p. 180-181. 
toute action militaire contre leur alliance. L'historien allemand Decker est allé jusqu'à parler d'une "perversion « du devoir de veiller au respect de la Constitution du Saint-Empire, qui avait été confié à la France par les traités de Westphalie, et de sa transformation par la France et la Suède en un droit à attendre des garanties de la part de l'Empire, leur permettant de couvrir leurs propres projets de politique offensive et expansive ${ }^{48}$. En 1672, le représentant français auprès de l'électeur de Mayence, Jacques de Gravel, avertit Louis XIV par courrier exprès »que, poursuivre ses conquêtes, c'était s'aliéner définitivement l'Allemagne «" La conséquence immédiate de cette aliénation fut l'échec des projets de renouvellement de la ligue du Rhin ${ }^{50}$.

Ce qui est extrêmement important, dans le contexte de notre étude de la connaissance du droit public allemand en France, c'est que le militaire reprit le dessus dans la diplomatie louis-quatorzienne et que les préoccupations de nature juridique, si importantes pour Richelieu, passèrent à l'arrière-plan. Ce changement d'attitude se reflète parfaitement dans la réponse que Louvois fit en 1688 à l'un de ses collaborateurs, qui lui avait proposé de s'assurer les forteresses situées sur le Rhin par des négociations plutôt que par leur conquête, afin de ménager l'opinion publique allemande. Le ministre lui rétorqua:

Otez-vous de l'esprit [...] que vous ayez rien à ménager avec les Allemands ni par amitié ni par modération; bien du canon, et des places dans leur pays les réduiront mieux que toute autre chose, et il n'y a de bons partis à prendre que ceux qui vous procureront ces avantages$1 a^{51}$.

Cela explique pourquoi, tout en répétant l'argumentation mise au point par Richelieu au sujet des libertés des princes d'Allemagne et de leur sûreté à travers l'alliance française, les ministres et les diplomates de Louis XIV n'aient pas su développer de manière considérable la théorie de la légitimation juridique de leur politique allemande. Cependant, dans leurs mémoires et notes, les collaborateurs du ministère des Affaires étrangères et les diplomates français dans l'Empire ne cessèrent pas pour autant d' analyser la situation politique de l'Allemagne et son droit public. Mais l'influence de leurs considérations sur la pratique politique française tendait à diminuer. L'heure n'était pas à la plume, mais à l'épée.

Au cours de la guerre de Hollande, plusieurs événements choquèrent profondément l'opinion publique allemande, sans que cela provoquât immédiatement une réaction politique forte de la part des états de l'Empire, puisqu'une grande partie d'entre eux se méfiaient toujours des velléités autoritaires de l'empereur, même

48 Cf. Klaus Peter DECKER, Frankreich und die Reichsstände 1672-1675. Die Ansätze zur Bildung einer »Dritten Partei « in den Anfangsjahren des Holländischen Krieges, Bonn 1981 (Pariser Historische Studien, 18), p. 64: »Entsprechend wurde nun die Garantiepflicht beider Mächte für den Erhalt der Friedensordnung zu einem Anspruch auf Garantieleistung durch das Reich bei der Durchsetzung eigener politischer Ziele pervertiert«.

49 BaDAlo-Dulong, Trente ans de diplomatie française, p. 177.

50 Cf. DECKER, Frankreich und die Reichsstände, p. 85-152.

51 Camille RousseT, Histoire de Louvois et de son administration politique et militaire, nouvelle édition, 4 vol., Paris 1862-1864, t. IV, p. 132-133, citation p. 133. 
au lendemain de la conclusion de la paix de Nimègue ${ }^{52}$. Si insensible fût-il dans un premier temps, le dépit que les ordres ressentirent face à certaines provocations françaises permit finalement à Léopold Ier de regagner la bienveillance de nombreux princes qui avaient depuis longtemps soutenu le parti français. Alors que, en 1635, Richelieu avait justifié la guerre contre l'Espagne par l'arrestation de son protégé, l'électeur de Trèves, ce furent les troupes françaises qui, en septembre 1673 , assiégèrent la résidence de ce même électeur et occupèrent la ville ${ }^{53}$. Les généraux français se souciaient peu du fait que ni l'électeur ni l'Empire n'étaient alors en guerre avec la France ${ }^{54}$. En novembre, Wilhelm Egon von Fürstenberg, ministre de l'archevêque de Cologne, avertit le secrétaire d'État aux Affaires étrangères Pomponne du fait que les opérations menées par l'armée française, placée sous le commandement de Turenne, avaient servi de prétexte à Léopold pour introduire ses propres troupes dans l'Empire avec l'assentiment plus ou moins explicite des ordres. À cela s'ajoutèrent l'occupation de la Décapole et celle de Germersheim, une ville qui appartenait à l'électeur palatin, en 1674. Le margrave Germain de Bade estima alors que les exactions commises par les troupes françaises au Palatinat avaient davantage profité à l'empereur que s'il eût remporté une victoire contre l'armée française ${ }^{55}$. Robert de Gravel, représentant français auprès de la diète de l'Empire à Ratisbonne, fut contraint à quitter l'Allemagne.

Toutefois, l'issue de la guerre de Hollande et la paix de Nimègue de 1678/1679 marquèrent l'apogée du prestige politique et militaire de Louis XIV en Europe.

52 Cf. Anton ScHINDLING, Reichstag und europäischer Frieden. Leopold I., Ludwig XIV. und die Reichsverfassung nach dem Frieden von Nimwegen (1679), dans: Zeitschrift für Historische Forschung 8 (1981), p. 159-177, ici p. 165, n. 25.

53 Au sujet de la détérioration des relations franco-tréviroises à partir des années 1670, cf. René PILlORGET, Jean-Hugues d'Orsbeck, électeur de Trèves, et la politique des réunions (1678-1688), dans: Revue d'histoire diplomatique 79 (1965), p. 315-337.

54 Contrairement à une idée reçue (qui est même soutenue dans certains manuels), certains historiens prétendent que l'Empire ne déclara jamais la guerre à la France pendant la guerre de Hollande. Pourtant, il est certain que, après le choc causé par les opérations françaises qui ne ménagèrent pas le territoire des ordres, traditionnellement alliés à la France, plusieurs votes de la diète sanctionnèrent la guerre de l'empereur contre Louis XIV et mirent à sa disposition les contingents des princes de l'Empire: cf. MüLLER, Zur Reichskriegserklärung; DEKKER, Frankreich und die Reichsstände, p. 377, n. 460; DuCHHARDT, Krieg und Frieden im Zeitalter Ludwigs XIV., p. 117-119; Christoph KaMPMANN, Reichstag und Reichskriegserklärung im Zeitalter Ludwigs XIV., dans: Historisches Jahrbuch 113 (1993), p. 41-59; BRAUN, Von der politischen zur kulturellen Hegemonie, p. 42.

55 Pour ces réactions allemandes, qui ne passèrent point inaperçues parmi les diplomates français, cf. DECKER, Frankreich und die Reichsstände, p. 232 et p. 356-360. Cf. également, d'une manière générale Martin WREDE, Das Reich und seine Feinde. Politische Feindbilder in der reichspatriotischen Publizistik zwischen Westfälischem Frieden und Siebenjährigem Krieg, Mayence 2004 (Veröffentlichungen des Instituts für Europäische Geschichte Mainz, Abteilung für Universalgeschichte, 196; Beiträge zur Sozial- und Verfassungsgeschichte des Alten Reiches, 15), troisième partie, chapitre 2: »Hostis imperii «: Die publizistische Auseinandersetzung mit Frankreich in den Kriegen Ludwigs XIV. (1667-1714) - vom Reichskrieg zum Kreuzzug?, p. 330-483. 
Outre les avantages que les traités de paix lui réservèrent, le Roi Très Chrétien put remporter un autre succès important en concluant une nouvelle alliance avec Frédéric-Guillaume, "Grand Électeur « de Brandebourg. Ce dernier s'était résigné à cette alliance à cause de la perte des conquêtes qu'il avait faites au détriment du roi de Suède, mais qu'il n'avait pu conserver dans la paix de Saint-Germain-enLaye, signée en 1679.

Si Nimègue mérite de passer pour l'heure de gloire de Louis XIV, cette paix ne marqua pas la fin de ses conquêtes. L'étape suivante de son expansion territoriale concernait l'Alsace, le Palatinat et l'électorat de Trèves. Ce fut l'heure des Réunions, tant attendue depuis 1648. Les activités du parlement de Besançon, du conseil souverain d'Alsace à Brisach et de la chambre de réunion de Metz ne purent fournir qu'une légitimation imparfaite aux prétentions du roi, qui dépassaient largement tous les titres juridiques qu'il avait obtenus à Münster. C'est pourquoi le roi ne réussit pas à conserver une grande partie des territoires qu'il revendiquait ${ }^{56}$. En 1681, l'occupation de Strasbourg, ville explicitement exceptée de la cession de l'Alsace à la France dans le traité de Münster, marqua le sommet et en même temps la fin de la politique d'expansion de Louis XIV. Dans les décennies à venir, celui-ci devait surtout chercher à défendre et à conserver ses acquisitions. Il les payait par un renforcement de la position de l'empereur en Allemagne. La dernière loi constitutionnelle du Saint-Empire, la constitution militaire de l'Empire (Reichskriegsverfassung), votée en 168157, mit à la disposition de l'empereur une armée de soixante mille hommes en temps de guerre.

Quoique plusieurs princes de l'Empire, comme les électeurs de Bavière et de Saxe, auxquels il faut ajouter Hanovre, se soient rapprochés de la cour de Vienne, après l'expérience des Réunions, la suprématie militaire incontestable de la France et le péril turc permirent à Louis XIV de conserver les conquêtes qu'il avait faites avant le $1^{\text {er }}$ août 1681 en Alsace, y compris Strasbourg, ainsi qu'au Luxembourg, d'abord pour une durée déterminée de vingt ans, comme le fixa la trêve de Ratisbonne, signée en 1684. Même s'il faut s'interroger sur le prix que le Roi Très Chrétien paya pour ces acquisitions, qui lui avaient effectivement aliéné l'amitié de nombreux princes, il en découla un indéniable avantage stratégique pour la ligne de forteresses de Vauban qu'elles venaient renforcer.

L'armée française eut bientôt l'occasion de s'en féliciter, puisque la trêve ne dura pas longtemps. En effet, dès 1688 , la succession palatine, pour laquelle Louis XIV prétendait défendre les droits d'Élisabeth-Charlotte d'Orléans, princesse Palatine et épouse du frère du roi, entraîna la guerre de la ligue d'Augsbourg, nom-

56 Cf. Marie-Odile PIQuet-Marchal, La chambre de réunion de Metz, Paris 1969 (Travaux et recherches de la Faculté de droit et des sciences économiques de Paris, Sciences historiques, 17), en particulier p. 106.

57 Helmut NeuHaus considère cette loi comme la dernière loi fondamentale du Saint Empire romain germanique; cf. ID., Das Problem der militärischen Exekutive in der Spätphase des Alten Reiches, dans: Johannes KUNISCH (dir.), Staatsverfassung und Heeresverfassung in der europäischen Geschichte der fruihen Neuzeit, avec le concours de Barbara STOLLBERG-RILINGER, Berlin 1986 (Historische Forschungen, 28), p. 297-346. 
mée d'après l'alliance qui s'était formée contre la France en juillet 1686, bien que celle-ci n'entrât jamais en vigueur ${ }^{58}$. Cette entreprise engagea le royaume dans un long conflit militaire qui dura jusqu'à la paix de Ryswick en 1697. L'objectif essentiel de Louis XIV était de conserver définitivement les acquisitions qui ne lui avaient été accordées que pour vingt ans par la trêve de Ratisbonne. Dans cette perspective, cette guerre souvent qualifiée de défensive comportait un élément offensif, dans la mesure où le roi cherchait un titre de possession illimité qu'il n'avait pas encore obtenu auparavant. Une autre pomme de discorde était l'admission de Guillaume de Fürstenberg dans le collège électoral, admission demandée par la France pour son protégé, quoique Fürstenberg n'eût pas réussi, en juillet 1688 , à obtenir la majorité des deux tiers, requise pour être proclamé archevêque de Cologne ${ }^{59}$.

Plus que par les objectifs de la politique française, l'opinion allemande fut choquée par les méthodes peu délicates mises en œuvre par l'armée du roi: une politique de la terre brûlée devait protéger la France de toute attaque sur une ligne le long du Rhin qui allait de Spire à Coblence ${ }^{60}$. La dévastation du Palatinat a laissé des traces bien vives dans la conscience collective allemande aux $\mathrm{XIX}^{\mathrm{e}}$ et $\mathrm{XX}^{\mathrm{e}}$ siècles. Même à l'époque des tensions nationalistes importantes entre la France et le Reich allemand, au XIX ${ }^{e}$ et au premier $\mathrm{XX}^{\mathrm{e}}$ siècle, l'historiographie française n'a pas caché son désaccord avec cette stratégie dévastatrice, que François Bluche, pourtant un grand admirateur du Roi-Soleil, est allé jusqu'à qualifier de »crime« en $1986^{61}$. André Corvisier a souligné le caractère systématique des destructions et des incendies, inégalés depuis la guerre de Trente Ans, qui constituent "une des questions les plus délicates de l'histoire des rapports franco-allemands « ${ }^{62}$. Le 3 avril 1689, la diète de l'Empire déclara la guerre à Louis XIV, ce

$58 \mathrm{Cf}$. Charles BouTANT, L'Europe au grand tournant des années 1680. La succession palatine, Paris 1985.

59 Fürstenberg avait obtenu treize voix, Joseph Clément de Bavière, neuf. Cf. BRAUBACH, Wilhelm von Fürstenberg, p. 421-448.

60 Cf. Bernd WundER, Frankreich, Württemberg und der Schwäbische Kreis während der Auseinandersetzungen über die Reunionen (1679-97). Ein Beitrag zur Deutschlandpolitik Ludwigs XIV., Stuttgart 1971 (Veröffentlichungen der Kommission für geschichtliche Landeskunde Baden-Württemberg, série B: Forschungen, 64), en particulier p. 81-200; Hermann WeBer, La stratégie de la terre brûlée: le cas du Palatinat en 1689, dans: La Vendée dans l'histoire. Actes du colloque [réuni à La Roche-sur-Yon, avril 1993], Paris 1994, p. 193-208. Cf. également Kurt vON RAUMER, Die Zerstörung der Pfalz von 1689 im Zusammenhang der französischen Rheinpolitik, Munich, Berlin 1930; Friedrich KLEYSER, Der Flugschriftenkampf gegen Ludwig XIV. zur Zeit des pfälzischen Krieges, Berlin 1935 (Historische Studien, 270; Forschungen zur Geschichte des Ancien régime und der großen Revolution, 6).

${ }^{61}$ François Bluche, Louis XIV, Paris 1999 [première édition: 1986], p. 665-666: "Au lieu de terroriser l'Empire, le sac du Palatinat le soude contre la France. [...] Le crime est mesurable à la surface des champs ravagés et des ruines noircies. L'erreur est, s'il se peut, plus grande que le crime. Les exagérations de la polémique protestante se trouvent effacées par les cruels excès des troupes françaises «.

62 Cf. André CoRvISIER, Louvois, Paris 1998 [première édition: 1983], p. 459-464, citation p. 460. 
qui fut un indéniable camouflet pour la politique allemande de la France, dont l'objectif avait été, tout au long du XVIIe siècle, de séparer les ordres de l'empereur. Or, en 1697, Ryswick permit encore une fois à la France de recueillir des avantages considérables, malgré la formation d'une grande coalition contre le royaume: en abandonnant la Lorraine, occupée en 1670 , et les réunions hors de l'Alsace, Louis XIV se vit définitivement confirmer la possession de l'Alsace et de Strasbourg. D'ailleurs, les états de l'Empire étaient représentés à Ryswick. Mais malgré leur ius pacis ac belli, à l'exception de ce congrès de paix, l'empereur avait toujours réussi à agir non seulement en son nom mais aussi en celui de l'Empire au cours des grands congrès internationaux de la deuxième moitié du XVII' siècle ${ }^{63}$.

On peut donc constater que, dans la deuxième moitié du XVIIe siècle, la puissance de la France permit à Louis XIV de remporter des succès importants et d'arrondir notablement la frontière est du royaume, tout en ménageant de moins en moins les princes allemands, avant qu'il ne se dirige vers une politique étrangère plus pacifique, à la fin du siècle. À ce moment-là, les négociations d'Ulric Obrecht avec les plénipotentiaires palatins et impériaux à Francfort donnèrent encore lieu, en France, à des réflexions approfondies sur le droit public du Saint-Empire.

Or, quatre ans après la conclusion des traités de paix de Ryswick, en 1701, la mort de Charles II ( $\dagger 1^{\text {er }}$ novembre 1700$)$ provoqua la guerre de la Succession d'Espagne. Les hommes d'État, les diplomates et les juristes de l'Europe entière avaient attendu cet événement depuis des décennies. Depuis 1668, toutes les tentatives pour trouver un compromis avant la mort du dernier roi d'Espagne de la maison d'Autriche et pour éviter la guerre avaient échoué. Bien qu'il s'agit d'une guerre dynastique européenne, ce long conflit qui occupa presque toute la fin du règne du Roi-Soleil fut d'une importance majeure pour les relations franco-allemandes en particulier. L'empereur put recueillir les fruits de l'amélioration de ses rapports avec les états de l'Empire, à laquelle la politique louis-quatorzienne avait largement contribué. Seuls les électeurs de Cologne et de Bavière soutinrent la France et furent mis au ban de l'Empire. Malgré la disposition de Louis XIV de sacrifier plusieurs petits états de l'Empire à l'électeur Max-Emmanuel de Bavière, la France ne rompit pas complètement avec sa politique allemande et ne chercha pas à détruire l'Empire, contrairement à ce qui se produisit sous la Révolution et sous Napoléon ${ }^{64}$. L'Empire se rangea derrière son chef. En 1704, la France essuya

${ }^{63}$ Cf. Klaus MaletTKe, Les traités de Westphalie comme système européen et le Saint Empire, dans: Soutou, VALENTIN (dir.), Le statut international de l'Allemagne, p. 647-662, ici p. 660 .

64 Pour les parallèles et pour les différences existant entre la politique allemande de Louis XIV et celle de la Révolution cf. Eckhard BudDRUss, Die Deutschlandpolitik der Französischen Revolution zwischen Traditionen und revolutionärem Bruch, dans: Karl Otmar Freiherr vON ARETIN, Karl HÄRTER (dir.), Revolution und konservatives Beharren. Das Alte Reich und die Französische Revolution, Mayence 1990 (Veröffentlichungen des Instituts für Europäische Geschichte Mainz, Abteilung Universalgeschichte, cahier suppl. 32), p. 145154 , en particulier p. $146-148$ et p. 151-154. 
une défaite importante à Höchstädt. Pour des raisons de sécurité, les associations des cercles de l'Empire (en l'occurrence, l'association de Nördlingen) imaginèrent alors de construire une »barrière de l'Empire « (Reichsbarriere) en récupérant les territoires cédés à Louis XIV, en particulier l'Alsace, voire en rétablissant la matricule de l'Empire de 1521, ce qui aurait inclus la reconquête des Trois-Évêchés lorrains ${ }^{65}$. Pourtant, dans la perspective des associations circulaires, il ne s'agissait pas d'une prétention à récupérer de vieux territoires allemands, mais de la création d'une ligne de défense contre la France ${ }^{66}$, projet qui en dit long sur le déclin du prestige de la royauté française, comme protectrice des états de l'Empire. En 1709 et en 1710, la situation de la France se dégrada fortement, et ce projet risquait effectivement de mettre en péril la frontière est du royaume. Louis XIV dut se résigner à autoriser ses plénipotentiaires de Gertruidenberg à rétrocéder la plus grande partie de l'Alsace. Mais ces pourparlers n'aboutissant pas à la paix, et la promesse faite par les puissances maritimes à l'archevêque de Mayence, directeur de l'association de Nördlingen, dans le traité du 22 août 1711, restant lettre morte, le projet de cette association ne fut pas réalisé67. Après les tournants que constituèrent la victoire des tories à Londres (1710) et surtout la mort de l'empereur Joseph Ier (17 avril 1711), la France put sauver l'intégrité territoriale du royaume et obtenir la réhabilitation des électeurs de Cologne et de Bavière, qui avaient payé au prix fort, par leur mise au ban de l'Empire, leur alliance avec Louis XIV68.

\section{La régence et le règne de Louis XV (1715-1756)}

La guerre avait eu pour conséquence que la France avait interrompu ses relations diplomatiques avec la plupart des princes de l'Empire, alors que celles-ci s'étaient considérablement intensifiées sous le règne du Roi-Soleil. Â la veille de la mort de Louis XIV, le réseau diplomatique français en Allemagne était donc à reconstruire. Après le $1^{\text {er }}$ septembre 1715 , la régence se montra hésitante à cet égard. Parfois, ce furent les princes de l'Empire eux-mêmes qui encouragèrent la France à envoyer ses représentants en Allemagne. Or, l'expérience avait montré au gouvernement français que certaines représentations diplomatiques, en particulier celle auprès de la diète impériale à Ratisbonne, avaient déçu les attentes françai-

65 Cf. Max Braubach, Um die »Reichsbarriere« am Oberrhein. Die Frage der Rückgewinnung des Elsaß und der Wiederherstellung Lothringens während des Spanischen Erbfolgekrieges [première publication en 1936], dans: ID., Diplomatie und geistiges Leben im 17. und 18. Jahrhundert. Gesammelte Abhandlungen, Bonn 1969 (Bonner Historische Forschungen, 33), p. 231-267.

66 Cf ibid., p. 233.

${ }^{67}$ Cf. ARETIN, Kreisassoziationen, p. 60-62.

${ }^{68}$ Au sujet des conférences de Gertruidenberg et des traités de paix d'Utrecht, de Rastatt et de Bade (1713/1714), cf. BÉly, Espions. 
ses dans le passé69. Ce ne fut donc qu'avec une certaine retenue, et en choisissant parfois des personnages d'une qualité sociale modeste, que la France envoya de nouveau ses diplomates auprès des princes de l'Empire et à la diète ${ }^{70}$. Parmi les missions les plus importantes, on comptait toujours les cours électorales de Berlin, de Cologne et de Munich. Le traité d'alliance avec la Bavière, en particulier, fut renouvelé en 1727 (après une brève interruption à partir de 1723), ainsi qu'en 1733 et en 1738. En 1734, la France conclut également un traité pour le paiement de subsides à l'électeur de Cologne.

Entre 1715 et 1730 environ, le système des relations internationales était marqué par une forte instabilité, qui se traduisit par la formation d'alliances éphémères. À cette époque, les cours de Vienne et de Versailles semblèrent parfois se rapprocher $^{71}$. En effet, les "analyses politiques du temps de Richelieu semblaient appartenir au passé depuis le règlement de la succession de Charles II d'Espagne en faveur des Bourbons. La France ne risquait plus l'encerclement par la maison d'Autriche « 72 . Fleury, principal ministre sans en avoir le titre, préconisait une réconciliation avec l'empereur. Mais les deux cours n'étaient pas encore prêtes à accomplir leur »révolution diplomatique«. En effet, les collaborateurs du ministère des Affaires étrangères et les diplomates français étaient encore tout imprégnés de la peur d'une renaissance de l'autorité impériale dans l'Empire et ne remettaient pas en question la priorité que représentait toujours le combat contre l'influence autrichienne en Allemagne et en Europe. L'étude des mémoires diplomatiques français de cette époque a montré la persistance de cette vieille conception de l'antagonisme entre Versailles et Vienne ${ }^{73}$, bien que l'autorité réelle de l'empereur se soit incontestablement affaiblie depuis le temps de François Ier et de Richelieu. L'évolution du rôle constitutionnel de l'empereur en tant que chef de l'Empire n'était donc pas toujours en phase avec sa perception par les responsa-

${ }^{69}$ Cf. UlbeRT, Frankreichs Deutschlandpolitik, en particulier p. 100-129. C'est désormais l'ouvrage de référence pour les relations franco-allemandes sous la Régence. Pour la suite, on se reportera toujours au grand travail de Max BRAUBACH, Versailles und Wien von Ludwig XIV. bis Kaunitz. Die Vorstadien der diplomatischen Revolution im 18. Jahrhundert, Bonn 1952 (Bonner Historische Forschungen, 2). Pour le Renversement des alliances dans les archives diplomatiques françaises et pour l'application de l'alliance entre Versailles et Vienne après 1756, cf. BUDDRUSS, Die französische Deutschlandpolitik; EXTERNBRINK, Friedrich der Große, Maria Theresia und das Alte Reich.

70 Cf. UlBerT, Frankreichs Deutschlandpolitik, p. 102-111 (diète de Ratisbonne), 132-151 (Autriche), 196-227 (Prusse), 268-277 (Bavière), 306-312 (Cologne).

71 Cf. Braubach, Versailles und Wien, p. 105-185.

72 Jean BÉRENGER rappelle que "Louis XIV avait, dans les derniers mois de son règne, souhaité un rapprochement avec l'empereur Charles VI, qui s'y refusa«; ID., Le traité de Versailles et le renversement des alliances, dans: Célébrations nationales 2006, délégation aux célébrations nationales (éd.) de la direction des archives de France, ministère de la Culture et de la Communication, Paris 2005, p. 35-37, ici p. 35. À ce sujet, cf. également BraUBACH, Versailles und Wien, p. 45-104. Pour des tentatives de rapprochement au XVIIe siècle, voir ibid., p. 7-44; Jean BÉRENGER, Une tentative de rapprochement entre la France et l'empereur. Le traité de partage secret de la Succession d'Espagne du 19 janvier 1668, dans: Revue d'histoire diplomatique 79 (1965), p. 291-314.

${ }^{73} \mathrm{Cf}$. UlBERT, Frankreichs Deutschlandpolitik, en particulier p. 328-348. 
bles politiques français et leurs collaborateurs. On constate en effet un décalage entre le moment où survenaient des changements dans l'Empire et le moment où ils étaient perçus en France. Le traumatisme de l'hégémonie habsbourgeoise était trop fortement ancré dans les esprits pour céder brusquement la place à de nouveaux paradigmes permettant d'interpréter différemment les rapports entre le roi de France et l'empereur.

Le caractère primordial du droit dans les relations entre la France et l'Empire était devenu un fait acquis. L'administration française en prit acte également, comme en témoigne la création d'une charge de jurisconsulte du roi pour le droit germanique $^{74}$, en 1723 . Or, à partir de 1731 , la rivalité franco-autrichienne réapparut au premier plan de la politique européenne. En effet, la cour de Vienne s'était dangereusement rapprochée de Londres, qui lui avait garanti le respect de la Pragmatique Sanction, dans le traité du 16 mars 1731. Afin d'obtenir la garantie anglaise pour l'héritage de Marie-Thérèse, Charles VI sacrifia d'autres intérêts politiques et économiques qui l'avaient opposé à la Grande-Bretagne. En 1733, des projets de guerre furent conçus à Versailles. Est-ce un hasard si l'»Histoire de l'Empire« de Jean Heiss fut précisément éditée quatre fois en 1731 et en 1733 ? Est-ce également un hasard si cet ouvrage ne fut plus jamais réédité après la fin du vieux système international fondé sur l'antagonisme entre Vienne et Versailles? Certes, on ne peut pas prouver un lien de cause à effet, mais la corrélation est évidente. Quoi qu'il en soit, la politique allemande redevint une priorité pour le ministère des Affaires étrangères au début des années 1730, et cette crise diplomatique entre les cours de Versailles et de Vienne éveilla certainement la curiosité du public à l'égard de l'Empire.

Dans la guerre de Succession de Pologne, qui résulta de cette crise, la France se fixa comme objectif l'acquisition de la Lorraine. L'Empire était directement concerné par les combats qui se déroulaient, entre autres, dans la région du haut Rhin, mais leurs conséquences pour les populations furent moins dramatiques qu'à l'époque des guerres de Louis XIV. L'empereur réussit de nouveau à obtenir de la diète une déclaration de guerre contre la France, au nom du Saint Empire romain germanique. Pourtant, le traité de Marly conclu en 1729 assura à la France le soutien des princes électeurs du Palatinat, de Bavière et de Cologne. En 1735, les préliminaires de Vienne apportèrent au royaume de France la Lorraine, qui était pourtant gouvernée par le beau-père de Louis XV jusqu'en 1766, alors que François de Lorraine, qui épousa en 1736 Marie-Thérèse, obtint le grand-duché de Toscane. À partir de l'acquisition de la Lorraine, et jusqu'à la Révolution française, le royaume de France ne poursuivit plus de projet d'agrandissement au détriment du Saint-Empire. Dès 1738, le marquis d'Argenson nota dans un mémoire sur les priorités politiques du royaume que le temps des conquêtes était fini. Cette

74 Cf. ID., Les Affaires étrangères françaises et la Constitution. Pour cette institution, voir également Jean-Pierre SAMOYAULT, Les bureaux du secrétariat d'État des Affaires étrangères sous Louis XV. Administration, personnel, Paris 1971 (Bibliothèque de la Revue d'histoire diplomatique, 3), p. 141-147, 193 et 302-303. 
renonciation à l'expansion sur le continent ${ }^{75}$, qui se distingue nettement des comportements des autres grandes puissances au cours de ce siècle, est une particularité qui mériterait une étude approfondie, comme le souligne Buddruss ${ }^{76}$. Le traité de Vienne conduisit en outre à une nouvelle entente entre l'Autriche et la France.

Pour autant, Fleury opéra surtout un rapprochement avec Frédéric-Guillaume

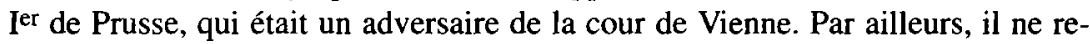
nonça point à l'alliance traditionnelle avec la Bavière. Après la mort de Charles VI, le 20 octobre 1740, l'Empire devint vacant et les pays héréditaires autrichiens tombèrent en quenouille. Malgré la promesse qu'elle avait faite à Charles VI de respecter la Pragmatique Sanction, la France soutint Charles Albert de Bavière, qui ne se portait pas seulement candidat à l'élection impériale, mais revendiquait aussi une partie de l'héritage autrichien. Pourtant, tout en saisissant l'opportunité de chasser les Habsbourg du trône impérial et de réaliser ainsi le rêve des rois de France vieux de plus de deux siècles, Fleury voulait certainement éviter que Charles Albert n'accumulât toute la puissance impériale et autrichienne et ne devienne un ennemi aussi redoutable que les Habsbourg. Selon lui, Marie-Thérèse devait donc conserver les pays héréditaires de la maison d'Autriche. En décembre 1740, l'invasion de la Silésie par Frédéric II de Prusse marqua le début de la guerre de Succession d'Autriche. Belle-Isle, qui fut au même moment envoyé à Francfort, lieu prévu pour l'élection impériale, rédigea deux mémoires en janvier 1741. L'ambassadeur préconisa un affaiblissement durable de l'Autriche, auquel la France devait aider à travers son alliance avec la Prusse. Toutefois, Belle-Isle envisageait comme Fleury non seulement l'éviction des Habsbourg de la tête de l'Empire, mais aussi la mise en place d'un équilibre des forces entre les Habsbourg et les Wittelsbach en Allemagne, qui éviterait la domination de ce pays par une seule grande puissance ${ }^{77}$. Pourtant, il était difficile de mettre en œuvre ce projet, puisque, tout en soutenant Charles Albert de Bavière, la France devait éviter la ruine totale de Marie-Thérèse. Grâce à sa stratégie militaire, la France parvint effectivement à éviter la catastrophe, et même à reprendre l'offensive dès $1742^{78}$.

75 À l'exception des différends concernant les frontières de l'Alsace, qui ne furent définitivement réglés que dans les traités conclus en 1766 avec l'électeur palatin Charles-Théodor et le duc Christian IV de Palatinat/Deux-Ponts. Toutefois, ces traités ne devaient entrer en vigueur qu'à la mort de l'électeur palatin, qui survécut à l'Ancien Régime († en 1799).

${ }_{76}$ Cf. BudDRuss, Die französische Deutschlandpolitik, p. 27-28.

${ }^{77}$ En particulier, en »born[ant] les conquêtes de l'Électeur [de Bavière] ainsi que celle du roi de Prusse«. Les deux mémoires de Belle-Isle des 22 et 27 janvier 1741 concernant le plan d'opérations militaires ont été publiés par Maurice SAUTAI, Les préliminaires de la guerre de la Succession d'Autriche, Paris 1907, p. 501-512 et p. 512-521, citation p. 502 (ibid., p. 133-153 pour le personnage de Belle-Isle). Cf. également Volker PRESS, Das wittelsbachische Kaisertum Karls VII. Voraussetzungen von Entstehung und Scheitern, dans: Andreas Kraus (dir.), Land und Reich, Stamm und Nation. Probleme und Perspektiven bayerischer Geschichte. Festgabe für Max Spindler zum 90. Geburtstag, 3 vol., Munich 1984 (Schriftenreihe zur bayerischen Landesgeschichte, 78-80), vol. II: Frühe Neuzeit, p. 201-234, en particulier p. 214.

$78 \mathrm{Cf}$. Volker PRESS, Frankreich und Bayem von der Reformation bis zum Wiener KongreB, 
En ce qui concerne l'élection impériale, la France remporta cette fois-ci son pari, en faisant élire l'électeur de Bavière Charles Albert, le 12 février 1742. Mais le règne de Charles VII, chassé de ses terres par les troupes de Marie-Thérèse, fut finalement une grande désillusion pour la France ${ }^{79}$, qui avait dépensé presque 5\% du budget annuel du royaume pour soutenir l'empereur Wittelsbach ${ }^{80}$. Après la mort subite de cet empereur, le 20 janvier 1745, les électeurs élirent de nouveau un Habsbourg (François de Lorraine) ${ }^{81}$. À partir de ce moment-là, le trône n'échappa plus à la maison d'Autriche jusqu'à la fin du Saint-Empire. La proposition du marquis d'Argenson de supprimer l'office de l'empereur, formulée au lendemain de la mort de Charles VII, ne fut finalement qu'une idée éphémère ${ }^{82}$, bien que le marquis l'eût déjà conçue en septembre $1741^{83}$. Avant la Révolution et

dans: DuchHARDT, SCHMiTT (dir.), Deutschland und Frankreich, p. 21-70, en particulier p. 55-56.

79 Cf. PRESS, Das wittelsbachische Kaisertum, en particulier p. 216-234.

80 Cf. HartmanN, Geld als Instrument europäischer Machtpolitik, p. 216-221 et p. 227.

81 Cf. Braubach, Versailles und Wien; Fritz Wagner, Kaiser Karl VII. und die großen Mächte 1740-1745, Stuttgart 1938.

82 Cf. AuerbaCh, La France et le Saint Empire romain germanique, p. 325-326; Auerbach cite la lettre envoyée par d'Argenson à La Noue, résident français auprès de la diète de l'Empire à Ratisbonne depuis 1738 , le 15 juillet 1745: On peut penser que l'anarchie serait un état fort heureux pour la plupart d'entre eux [des princes allemands]; chacun y vivrait libre et sous des lois communes aisées à maintenir. [...] On en voit des exemples bien sensibles dans les Républiques des Suisses et des Provinces Unies [...]. Sondez adroitement quelques-uns des Ministres les plus raisonnables à Francfort sur cette vue, pour voir s'il serait possible d'imaginer que la Diète Électorale pût, nonobstant la Bulle d'or, se dispenser de donner un chef à l'Empire. Vous pouvez feindre que cette idée vous ait été communiquée par quelque jurisconsulte«. La Noue répondit que les Allemands tenaient à élire un nouvel empereur; cf. la réponse envoyée par La Noue au ministre, le 28 juillet 1745: „Chacun le [sc. l'empereur] regarde comme le protecteur et le bouclier des faibles contre l'oppression des plus puissants«. Alors que les Allemands préparaient l'élection de François-Étienne de Lorraine, époux de Marie-Thérèse d'Autriche, élu le 13 septembre et couronné le 4 octobre 1745, d'Argenson dissertait toujours sur une Allemagne républicaine; $c$ f. sa lettre à La Noue du 17 août 1745: »Une association libre comme celle des Cantons Suisses et des Provinces Unies protégerait aussi sûrement l'innocence et ne serait pas sujet aux mêmes inconvénients que l'assujettissement forcé à l'autorité impériale. [...] Tous [les princes] se trouveraient exempts de rechercher, en s'abaissant lâchement devant les ministres de la cour impériale, la faveur et quelques grâces de l'Empereur régnant«. D'Argenson estimait que le chef du corps germanique »en sera toujours plutôt le loup dévorant que le défenseur «.

83 Cf. [René de Voyer de Paulmy] marquis D'ARGENSON, Journal et mémoires du marquis d'Argenson, publiés pour la première fois d'après les manuscrits autographes du Louvre pour la Société de l'histoire de France par E. J. B. RaTHERY, 9 vol., Paris 1859-1867, ici vol. III, p. 384-385, 5 septembre 1741: "On ne doute pas, à présent, de notre traité avec la Prusse et la Bavière pour dépouiller à frais communs la reine de Hongrie, et pour revêtir l'électeur de Bavière de la dignité impériale, quoiqu'il fût tout à souhaiter qu'il n'y eût plus que des rois en Allemagne. Cette dernière promesse, faite sans doute à l'électeur de Bavière, pourra s'annuler par l'obstacle qu'y mettra le roi de Prusse, lequel, voyant qu'il ne peut être empereur et que Bavière augmente en possessions, s'opposera à ce que cette maison, déjà puissante, devienne encore trop forte par la dignité dont il s'agit; ainsi son suffrage relèvera nos promesses indiscrètes. J'ajouterai à cela que la reine de Hongrie elle-même, voyant que son époux ne peut être empereur, sera charmée qu'un autre ne le soit pas: ainsi s'abolira cette di- 
Napoléon, la France n'eut pas l'intention de supprimer l'office de l'empereur, ni de détruire le Saint-Empire. Toutefois, la non-ingérence préconisée par le marquis d'Argenson au lendemain de la guerre ${ }^{84}$ ne devint pas non plus un pivot de la politique allemande du royaume, puisqu'en 1756/1757 Louis XV n'hésita pas à combiner une guerre continentale, que la France menait surtout dans l'Empire, en particulier dans l'électorat de Hanovre, avec une guerre maritime contre l'Angleterre.

À la fin de la guerre de Succession d'Autriche, les alliés allemands de la France s'avérèrent des soutiens politiques et militaires peu fiables. Maximilien III Joseph, le nouvel électeur de Bavière, conclut la paix avec Marie-Thérèse. Pour sa part, Frédéric le Grand s'assura définitivement la Silésie par la paix de Dresde, signée le 15 décembre 1745. La France n'obtint presque rien, si ce n'est l'enrichissement de sa langue par une nouvelle expression: se battre "pour le roi de Prusse $\ll^{85}$, et la cession de Parme à l'infant Philippe, beau-fils de Louis XV, fixée par la paix d'Aix-la-Chapelle en 1748. Il est vrai qu'il manquait à la France un véritable objectif de guerre; une fois le rêve impérial transformé en cauchemar, les conquêtes que Maurice de Saxe fit aux Pays-Bas autrichiens au nom de la France se dirigèrent en réalité plus contre la puissance maritime de l'Angleterre que contre l'Autriche.

Ce changement ne doit pas passer inaperçu: au lendemain de la paix de Westphalie et presque tout au long du règne de Louis XIV, la perception française du Saint-Empire était étroitement liée au combat de celui-ci contre l'Espagne. Dans un premier temps, l'Espagne fut même le principal adversaire de la France, et ce n'est qu'au moment des Réunions en Alsace et dans le sud-ouest de l'Allemagne que l'Empire passa au premier plan. Or, au milieu du XVIII e siècle, le principal adversaire de la France était incontestablement l'Angleterre. À Versailles, on interprétait donc les évolutions dans l'Empire selon les conséquences qu'elles pouvaient avoir sur les rapports de force entre la France et la Grande-Bretagne. Toutefois, ce prisme ne détermina pas la perception française du Saint-Empire de la même façon que l'antagonisme franco-espagnol aux XVIe et XVIIe siècles, puisque, tout en tenant l'électorat de Hanovre, l'Angleterre n'entretenait pas de relations aussi étroites avec l'Allemagne que ne l'avaient fait les Espagnols à l'époque des rois de la maison d'Autriche. Dans l'évolution du système international au XVIII siècle, on observe donc deux transformations fondamentales, dans le cadre desquelles il faut étudier les réflexions des Français sur le Saint-Empire:

gnité incommode qui s'était perpétuée depuis Charlemagne, et qui tyrannisait également par ses droits l'Allemagne et l'Italie, qui offusquait la grandeur de notre monarchie, quoiqu'elle fût sortie de nous et qu'elle eût été inventée pour décorer l'empire des lys «.

84 Zevort cite la recommandation suivante du marquis d'Argenson: "Cessons nos vues sur l'Allemagne, laissons l'Empire en repos, il nous y laissera de même; l'empereur [Charles VII] nous a plus coûté à protéger et à créer qu'il ne nous en coûterait jamais si l'Empire voulait nous détruire «; citée d'après Edgar ZEVORT, Le marquis d'Argenson et le ministère des Affaires étrangères du 18 novembre 1744 au 10 janvier 1747, Genève 1976 (réimpression de l'édition de Paris 1880), p. 285.

${ }^{85}$ Cf. Michel AnToIne, Louis XV, Paris 1989, p. 402. 
d'une part, le dualisme entre l'Autriche et la Prusse dans l'Empire même, et, d'autre part, le début de la prépondérance des cinq grandes puissances au niveau européen (France, Angleterre, Autriche, Prusse et Russie), qui remplaça le vieil antagonisme entre la France et les Habsbourg ${ }^{86}$.

Depuis 1740 et surtout à partir de sa victoire contre les Autrichiens à Mollwitz en 1741, l'essor de la Prusse et son importance fondamentale pour le système d'alliances que la France avait construit dans l'Empire devinrent de plus en plus évidents. Mais les moyens traditionnellement employés par la diplomatie française à l'égard des princes de l'Empire ne produisirent pas les mêmes effets dans le cas de la Prusse, puisque Frédéric II veilla à l'indépendance de sa politique et n'hésita pas à abandonner la France à plusieurs reprises ${ }^{87}$. Louis XV toléra cette attitude jusqu'à la conclusion du traité de Westminster entre la Prusse et l'Angleterre en 1756. Au siècle des Lumières, il est important de noter qu'avant 1756 et même après ce tournant dans l'histoire diplomatique la Prusse était considérée comme l'alliée »naturelle « de la France, au même titre que la Bavière. Or, en 1745, l'électorat de Bavière cessa provisoirement d'être l'allié de la France et perdit durablement une grande partie de sa puissance et son importance stratégique dans les réflexions du ministère français des Affaires étrangères. De toute évidence, l'ennemi le plus redoutable de la maison d'Autriche était Frédéric le Grand.

Pourquoi, en 1756, la France conclut-elle donc avec l'Autriche une alliance jugée »contre nature « par ses détracteurs contemporains et par les révolutionnaires de 1789, qui y virent un signe de la décadence de la royauté française? Dans le cadre de ce chapitre qui n'est qu'une synthèse des relations franco-allemandes de 1648 à 1756 , nous ne pouvons que rappeler certaines explications fondamentales et évoquer très brièvement quelques différends historiographiques. Le terme de »Renversement des alliances « désigne la conclusion de l'alliance défensive puis offensive qui fut signée entre Versailles et Vienne en 1756 et 1757 et l'application de ces traités, dont au moins le premier traité défensif resta en vigueur jusqu'en 1792. L'historiographie allemande appelle ce revirement des alliances la »révolution diplomatique « (diplomatische Revolution) de 1756. Le caractère »révolutionnaire « de cette nouvelle alliance résidait dans le fait que deux puissances s'allièrent en dépit de leur antagonisme traditionnel, qui avait été quasi axiomatique dans la politique européenne depuis Charles Quint et François I ${ }^{\text {er. Pourtant, Max }}$ Braubach a montré que cette alliance fut précédée de plusieurs tentatives de rap-

${ }^{86} \mathrm{Au}$ sujet de l'évolution du système des grandes puissances au XVIII ${ }^{e}$ siècle, cf. Derek McKAY, H[amish] M. SCOTT, The Rise of the Great Powers 1648-1815, Londres, New York 1983; Heinz DuchHARdT, Balance of Power und Pentarchie. Internationale Beziehungen 1700-1785, Paderborn et al. 1997 (Handbuch der Geschichte der internationalen Beziehungen, 4). Pour les origines du conflit maritime qui oppose la France à l'Angleterre à partir de 1726, cf. Armin REESE, Europäische Hegemonie und France d'outre-mer. Koloniale Fragen in der französischen Außenpolitik 1700-1763, Stuttgart 1988 (Beiträge zur Kolonial- und Überseegeschichte, 42); cf. également ID., Europäische Hegemonie versus Weltreich. AuBenpolitik in Europa 1648-1763, Idstein 1995 (Historisches Seminar, nouv. sér., 7), en particulier p. 54-73.

${ }^{87}$ Pour sa biographie, cf. Jean-Paul BLED, Frédéric le Grand, Paris 2004. 
prochement entre les cours de Versailles et de Vienne, depuis le début du XVIIIe siècle $^{88}$. Alors que, au cours de la guerre de Succession d'Autriche, le roi de Prusse avait signé deux fois une paix séparée, lors des conférences pour la paix d'Aix-la-Chapelle, l'Angleterre lui avait procuré la garantie internationale de son acquisition de la Silésie, froissant ainsi son allié autrichien. Les deux alliances traditionnelles (entre la France et la Prusse d'un côté, et l'Autriche et l'Angleterre de l'autre) avaient donc des fissures depuis les années 1740.

Pour Max Braubach, 1756 était l'aboutissement du vieux rêve de l'unité des deux plus grandes puissances catholiques. Toutefois, l'historiographie récente invite à ne pas exagérer le changement d'époque que constitue le Renversement des alliances $^{89}$. En effet, tout en plaidant depuis longtemps en faveur de cette nouvelle alliance, le chancelier autrichien Kaunitz imagina jusqu'à la fin des alternatives à ce retournement. Du côté français, les historiens ont également insisté sur l'indécision qui régnait à Versailles à la veille de la signature de cette alliance. En 1755, on examina encore à Versailles une éventuelle invasion française des Pays-Bas autrichiens. Cependant, l'alliance avec l'Autriche représentait pour Louis XV une affaire qui lui tenait particulièrement à cœur. Il vénérait Marie-Thérèse. Même s'il n'est pas encore connu dans ses moindres détails, le rôle décisif de $\mathbf{M}^{\mathrm{me}}$ de Pompadour, pourtant peu instruite des affaires politiques et en particulier de l'Allemagne $^{90}$, a souvent été souligné, et parfois peut-être même exagéré ${ }^{1}$. Les véritables négociations avec Kaunitz et l'ambassadeur autrichien Starhemberg furent menées par Bernis, un diplomate inexpérimenté 92 . Du fait de l'opposition que l'on attendait de leur part, dans un premier temps, les responsables officiels du ministère des Affaires étrangères furent tenus à l'écart des décisions les plus importantes, afin de ne pas compromettre le succès des pourparlers. Kaunitz considérait le ministre des Affaires étrangères, Rouillé, et le ministre de la Guerre, d'Argenson (le frère de l'ancien ministre des Affaires étrangères déjà cité), comme des représentants du "vieux système « ${ }^{93}$. De toute évidence, en 1756, les contemporains n'avaient pas le sentiment de `changer d'époque ‘. Ces particularités invitent à ré-

${ }^{88} \mathrm{Cf}$. le grand classique sur la »diplomatische Revolution« de BRAUBACH, Versailles und Wien.

${ }^{89}$ Rappelons que pour notre étude, la publication des ouvrages de Scheid et de Pfeffel constitue le véritable motif de la coupure entre 1754 et 1756 et que, dans cette perspective, le Renversement des alliances ne revêt qu'une importance secondaire. C'est pourquoi nous renonçons à évoquer un grand nombre d'études spécialisées. Dernier bilan historiographique: Braun, Von der politischen zur kulturellen Hegemonie, p. 90-100. Pour l'analyse critique de la position de Kaunitz, cf. Lothar SchILLING, Kaunitz und das Renversement des alliances. Studien zur außenpolitischen Konzeption Wenzel Antons von Kaunitz, Berlin 1994 (Historische Forschungen, 50).

90 Cf. BudDruss, Die französische Deutschlandpolitik, p. 43, n. 190.

91 Toutefois, il est certain qu'elle »joua, dans le renversement des alliances, un rôle discret, mais efficace«; BÉRENGER, Le traité de Versailles, p. 36.

92 François-Joachim Pierre de Bernis (1715-1794), ancien ambassadeur français en Pologne, puis à Venise de 1752 à avril 1755; ministre des Affaires étrangères du 28 juin 1757 jusqu'en décembre 1758; cardinal en octobre 1758; disgrâce fin 1758.

93 Braubach, Versailles und Wien, p. 427. 
pondre plus prudemment à la question de savoir dans quelle mesure l'alliance avec l'Autriche constitua réellement un changement de paradigme pour la France. Sans minimiser l'importance de l'événement, on doit noter que cette alliance ne reçut qu'un soutien modéré de la part des diplomates français après la guerre de Sept Ans et surtout après l'avènement de Louis XVI, qui n'avait pas la même passion pour l'Autriche que son prédécesseur. Parfois qualifiée de simple alliance »de façade «, puisque la France continuait à favoriser secrètement Frédéric II (sans concertation formelle des politiques française et prussienne), la longévité de l'alliance avec l'Autriche contredit cependant la thèse d'un simple >accident< de la politique française en 1756. En effet, pour les deux partenaires, cette alliance avait un but défensif et une fonction très concrète dans le maintien de la paix: à travers elle, la France pouvait limiter les effets de la politique expansive de l' Autriche et priver l'Angleterre d'un éventuel allié sur le continent; à Vienne, on était conscient d'empêcher par cette alliance une collaboration plus étroite entre Versailles et Potsdam.

Jean Bérenger estime que le traité de Versailles du $1^{\text {er }}$ mai 1756 »a profondément modifié l'équilibre européen jusqu'à la Révolution française «. Outre la réconciliation des maisons de Bourbon et de Habsbourg-Lorraine, cette alliance apporta »un demi-siècle de paix à la Rhénanie, aux Pays-Bas autrichiens, à l'Italie du Nord et aux provinces françaises du Nord-Est«, facilitant »' essor économique et culturel de ces régions au cours de la seconde moitié du XVIII ${ }^{e}$ siècle ${ }^{94}$.

L'alliance franco-autrichienne fut essentiellement initiée à Vienne. C'est sur la recommandation de Kaunitz que la conférence secrète chargea l'ambassadeur autrichien Starhemberg d'offrir un traité d'alliance à Louis XV95, le 21 août ${ }^{96}$. En dépit d'une première réponse française aux propositions autrichiennes du 9 septembre 1755 , jugée insuffisante, Kaunitz continua les négociations et enregistra un premier succès quand la France lui proposa un traité de neutralité et de garantie, le 28 décembre. De cette façon, l'Autriche n'était plus obligée de déclarer la guerre à l'Angleterre et les Pays-Bas autrichiens se trouvaient à l'abri d'une invasion française. La signature du traité de Westminster par Frédéric II, le 16 janvier 1756, fut considérée par le roi de France comme un affront. De plus, même »si Frédéric II n'avait pas l'intention d'abandonner l'alliance française, l'alliance prussienne n'était plus d'aucune utilité pour Louis $\mathrm{XV}$, au cas où le roi de Prusse refuserait d'attaquer le Hanovre ${ }^{97}$. Néanmoins, plusieurs diplomates de grand talent, dont Vergennes, futur ministre des Affaires étrangères, et Bussy, premier commis du dépôt des archives, continuèrent à se déclarer en faveur de la prolongation de l'alliance avec la Prusse conclue le 5 juin 1741. Cependant, le Conseil

94 BÉRENGER, Le traité de Versailles, p. 37.

95 Les historiens ne sont pas d'accord sur l'importance des quelques >signaux < donnés par Versailles à Vienne, par l'intermédiaire de Mayence.

96 Cf. Gustav Berthold Volz, Georg KüNTZEL (éd.), Preussische und österreichische Acten zur Vorgeschichte des Siebenjährigen Krieges, Leipzig 1899 (Publicationen aus den K. Preussischen Staatsarchiven, 74), en particulier p. LXXVI et p. 145-164.

97 BÉRENGER, Le traité de Versailles, p. 37. 
d'État décida le 4 février 1756 de ne pas prolonger cette alliance. Les historiens ont évalué de manière différente l'importance des facteurs psychologiques sur cette décision. Mais peut-on vraiment reprocher à Louis XV de ne pas avoir pardonné à son vieil allié son énième infidélité? Quoi qu'il en soit, ce ne fut qu'en 1769 que la France rétablit ses contacts diplomatiques avec la Prusse.

Or, la rupture de l'alliance avec la Prusse ne devait pas nécessairement conduire à la conclusion du traité défensif avec l'Autriche. Mais Versailles et Vienne réussirent effectivement à décider des derniers différends, au cours de pourparlers menés par Starhemberg avec Bernis et les responsables du ministère des Affaires étrangères, en particulier avec le ministre Rouillé. Le $1^{\text {er }}$ mai 1756, ces trois personnages signèrent à Jouy-en-Josas le traité d'alliance défensive et de neutralité, qui se transforma en alliance offensive le $1^{\text {er }}$ mai 1757. La France intervint dans la guerre de Sept Ans comme alliée de l'Autriche. Pour Louis XV, cette guerre fut »une opération désastreuse «, puisque le royaume eut »à combattre sur deux fronts, sans autre but de guerre que d'aider Marie-Thérèse«. En effet, il était en même temps engagé dans un conflit maritime qui l'opposait à l'Angleterre. Le roi »accumula les défaites sur terre et sur mer ${ }^{98}$. De la fin de la guerre de Sept Ans à la Révolution, les diplomates et les ministres français ont souvent jugé néfastes les conséquences de cette alliance, sans toutefois l'abroger ${ }^{99}$. En ce qui concerne les relations de la France avec les princes de l'Empire, on note que la diplomatie française se désintéressa dans une certaine mesure de ses alliés traditionnels, en rompant définitivement avec la politique des subsides et en ne soutenant que tièdement la Prusse ${ }^{100}$.

Nous avons vu que les représentants du ministère des Affaires étrangères n'exercèrent pas une influence prépondérante sur les négociations qui conduisirent au Renversement des alliances. Cependant, les rapports et les notes politiques des collaborateurs du ministère et des diplomates français laissent penser que l'image de l'Empire et en particulier de l'empereur s'était modifiée chez les hommes d'État et les diplomates français ${ }^{101}$. Mais, le fait qu'après 1763 , les mémoires du ministère fassent souvent état d'une perception de la politique impériale typique des orientations antihabsbourgeoises >classiques< de la France nous invite à une grande prudence.

Nous ne dirions pas que le Renversement des alliances a été la conséquence nécessaire d'une nouvelle perception du rôle constitutionnel qui incomba à l'empereur après 1740. Mais il semble cependant incontestable que la perception du rôle de l'office impérial, qui paraissait plus anodin pour la France qu'au temps de

98 Ibid.

99 BuDDRuss a montré que dans les mémoires du Quai d'Orsay on revenait souvent aux mêmes reproches contre la maison d'Autriche, qui avaient déjà caractérisé la pensée politique au ministère avant le Renversement des alliances; cf. ID., Die französische Deutschlandpolitik, passim.

100 Cf. ibid.

101 À ce sujet, cf. aussi ExtERnBRINK, Friedrich der Große, Maria Theresia und das Alte Reich. 
Charles Quint et de Ferdinand III, a contribué à rendre possible cette "révolution diplomatique «. Bien que nous excluions une déduction téléologique du Renversement des alliances d'après les mémoires politiques conservés au ministère des Affaires étrangères, ces documents montrent toutefois que, dans les années 1750, la nouvelle alliance avec l'Autriche n'était pas pour Versailles une décision sans alternative, mais plutôt une possibilité parmi d'autres. Par contre, pour François Ier ou pour Richelieu, une telle option aurait été catégoriquement exclue. 